\title{
Noncanonical Functions and Cellular Dynamics of the Mammalian Signal Recognition Particle Components
}

\author{
Camilla Faoro ${ }^{\dagger}$ and Sandro F. Ataide* \\ School of Life and Environmental Sciences, The University of Sydney, Sydney, NSW, Australia
}

OPEN ACCESS

Edited by:

Elsa Zacco,

Italian Institute of Technology (IIT), Italy

Reviewed by:

Roberto Giambruno,

Italian Institute of Technology (IIT), Italy Laura Broglia,

Italian Institute of Technology (IIT), Italy

*Correspondence:

Sandro F. Ataide

sandro.ataide@sydney.edu.au

${ }^{\dagger}$ Present address: Infection and Immunity Program and Department of Biochemistry and

Molecular Biology, Biomedicine Discovery Institute, Monash University,

Clayton, VIC, Australia

Specialty section:

This article was submitted to Protein and RNA Networks,

a section of the journal

Frontiers in Molecular Biosciences

Received: 12 March 2021 Accepted: 29 April 2021

Published: 25 May 2021

Citation:

Faoro C and Ataide SF (2021) Noncanonical Functions and Cellular Dynamics of the Mammalian Signal Recognition Particle Components.

Front. Mol. Biosci. 8:679584. doi: 10.3389/fmolb.2021.679584
The signal recognition particle (SRP) is a ribonucleoprotein complex fundamental for cotranslational delivery of proteins to their proper membrane localization and secretory pathways. Literature of the past two decades has suggested new roles for individual SRP components, 7SL RNA and proteins SRP9, SRP14, SRP19, SRP54, SRP68 and SRP72, outside the SRP cycle. These noncanonical functions interconnect SRP with a multitude of cellular and molecular pathways, including virus-host interactions, stress response, transcriptional regulation and modulation of apoptosis in autoimmune diseases. Uncovered novel properties of the SRP components present a new perspective for the mammalian SRP as a biological modulator of multiple cellular processes. As a consequence of these findings, SRP components have been correlated with a growing list of diseases, such as cancer progression, myopathies and bone marrow genetic diseases, suggesting a potential for development of SRP-target therapies of each individual component. For the first time, here we present the current knowledge on the SRP noncanonical functions and raise the need of a deeper understanding of the molecular interactions between SRP and accessory cellular components. We examine diseases associated with SRP components and discuss the development and feasibility of therapeutics targeting individual SRP noncanonical functions.

Keywords: signal recognition particle, ribonucleoproteins, RNA-binding proteins, co-translational targeting, noncanonical functions

\section{INTRODUCTION}

The precise cellular localization of nascent proteins is an essential process required for maintaining homeostasis, cell organization and survival (Hartl et al., 2011). Proteins can be delivered to their correct compartment during (co-translational) or after (post-translational) their biosynthesis in the cytoplasm. Roughly $30 \%$ of the proteome is initially destined to the endoplasmic reticulum (ER) in eukaryotes or the plasma membrane in bacteria. The main pathway for proteins to enter the ER is via co-translational translocation. Co-translational protein export is an efficient process that exquisitely interconnects protein translation with cell compartmentalization to circumvent challenges in folding and processing that newly nascent polypeptide may face if released into the cytoplasm (Hegde and Keenan, 2011). Given the complexity of these tasks, the cell has evolved specialized machines to achieve this goal (Cross et al., 2009).

The co-translational pathway utilizes the Signal Recognition Particle (SRP), an essential molecular machinery that couples the synthesis of nascent proteins to their proper secretory pathway and membrane localization (Akopian et al., 2013). Since the postulation of the "signal hypothesis" in 1971 and its discovery in 1980 by Walter and Blobel, SRP has been extensively investigated across diverse research fields focusing on its structure and molecular translocation function (Akopian et al., 2013). However, in the last 20 years, 


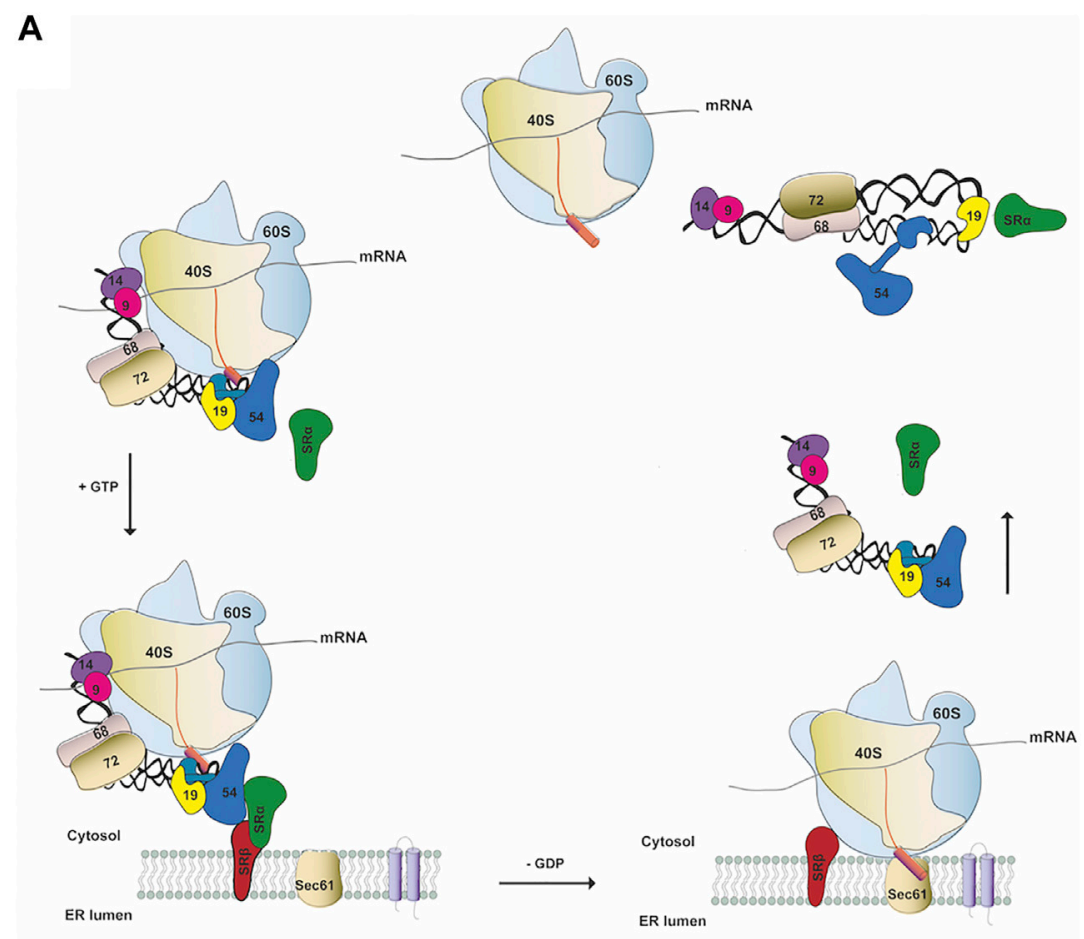

B

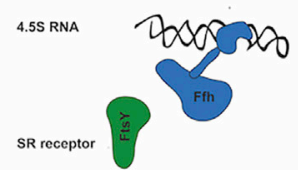

Eubacteria

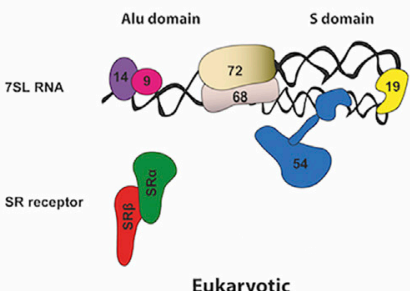

Eukaryotic

FIGURE 1 | SRP canonical cycle and composition (A) Schematic representation of co-translation protein targeting pathway in mammals. SRP binds the signal sequence (pink cylinder) as it emerges from the ribosome forming an RNC-SRP complex that docks in a GTP-dependent manner with the ER membrane by binding to the cognate SRP receptor (SR $\alpha / \beta)$. Following GTP hydrolysis, the RNC is transferred to the Sec61 translocon resulting in translocation of the nascent chain through the Sec61 pore and disassemble of SRP-SR complex (B) Schematic representation of SRP and SR components in the two kingdoms of life. On the left panel it is shown the eubacterial SRP complex and on the right the eukaryotic one (e.g., human SRP).

multiple studies have identified the SRP components in new interactions outside the co-translational translocation machineries, suggesting new roles for its components in regulating multiple pathways.

Noncanonical functions associated with RNA-binding proteins (RBPs) and ribonucleoprotein complexes (RNPs) are not unusual and ever since their discoveries, several studies have uncovered a new universe of RNA-biding activities. For instance, telomerase has been associated with extratelomeric properties that are independent of its role in telomere extension, implicating selective-telomerase targeted cancer therapies ( $\mathrm{Li}$ and Tergaonkar, 2014). Cajal body-specific RNPs (scaRNPs), which play a role in the biogenesis of small nuclear RNPs (snRNPs), have been proposed to act as regulatory RNPs (regRNPs) that contribute to ribosome heterogeneity (Poole et al., 2017).
The role of SRP components in cellular events outside cotranslation translocation, such as cell growth, differentiation and death, remain largely unexplored and underappreciated in mammalian cell biology. This review will discuss for the first time the emerging noncanonical roles of SRP components in mammalian cells reported to date, along with their association with cancer, autoimmune and genetic diseases.

\section{CANONICAL SRP PATHWAY}

\section{The SRP Cycle and Its Composition}

The canonical role of SRP involves co-translational targeting of secretory proteins to the ER in eukaryotes or to the plasma membrane in prokaryotes. The SRP-dependent protein 
pathway involves a series of sequentially regulated steps (Figure 1A). Proteins destined to enter the secretory pathway typically possess N-terminal hydrophobic signal sequences, which direct them to their target membrane (Rapoport, 2007). During the SRP cycle, SRP recognizes the hydrophobic signal peptide emerging from the exit tunnel of the translating ribosome and forms a ribosome nascent chain (RNC)-SRP complex (Pool et al., 2002; Halic et al., 2006). In eukaryotes, recognition of the signal sequence by SRP leads to arrest of the elongation of the polypeptide chain (elongation arrest) (Walter and Blobel, 1981). The RNC-SRP complex then docks in a GTP-dependent manner with its cognate SRP receptor (SR) on the target membrane. The signal peptide is released from SRP and the RNC is transferred to the translocon machinery (SecYEG in prokaryotes and Sec61p in eukaryotes). Meanwhile, translation resumes and the newly synthesized protein is delivered into the ER or plasma membrane (Saraogi and Shan, 2011). GTP hydrolysis by SRP: SR causes their dissociation and recycle for further rounds of targeting (Connolly et al., 1991).

SRP is a universally conserved ribonucleoprotein complex (RNP) found in all domains of life that has evolved its composition and function to become more complex and sophisticated in eukaryotes (Pool, 2005). However, the central ribonucleoprotein core and the general mechanism of SRP targeting are highly conserved. Bacteria contains the simplest and smallest SRP, comprising the universally conserved SRP54 protein (called Ffh) and the shorter 4.5S RNA (Figure 1B, left panel). Mammalian SRP is the most complex particle and consists of a long noncoding RNA (lncRNA) of approximately 300 nucleotides, the 7SL RNA, and six protein subunits named according to their apparent molecular weight: SRP9, SRP14, SRP19, SRP54, SRP68, and SRP72 (Figure 1B, right panel) (Peter Walter, 1983). The mammalian SR is a heterodimer composed of two subunits, SRa and SR $\beta$. SRa is a $69 \mathrm{kDa}$ peripheral membrane protein while $\mathrm{SR} \beta$ is a $25 \mathrm{kDa}$ integral ER membrane protein (Tajima et al., 1986). SRa regulates the SRP targeting cycle by interacting with SRP54 and with the translocon, while $\operatorname{SR} \beta$ is responsible to target the SRP at the ER membrane. Notably, SRa is universally conserved while $\operatorname{SR} \beta$ subunit is exclusive to eukaryotes. FtsY (Filamentation temperature sensitive X), the SR bacterial receptor, is the functional homologue of the mammalian SRa (Miller et al., 1994).

The eukaryotic SRP can be separated into two structural and functional domains, the Alu and S domains (Figure 1B, right panel) (Gundelfinger et al., 1983). The Alu-domain is formed by the $5^{\prime}-3^{\prime}$ end of the SRP 7SL RNA, SRP9 and SRP14 subunits and is responsible for arresting translation elongation (Weichenrieder et al., 2000). The S-domain is responsible for protein translocation activities by recognition of the signal sequence and for GTP-dependent interaction with the receptor and comprises the central region of the SRP 7SL RNA, proteins SRP19, SRP54, SRP68 and SRP72 (Walter and Blobel, 1983).

\section{Structural Highlights of the SRP Components}

7SL RNA has an architectural and enzymatic role in SRP assembly and acts as a central regulator of the SRP function, mediating global reorganization of the SRP in response to cargo binding and molecular communication with the cognate receptor. The 7SL SRP RNA folds into a double-stranded secondary structure with a cruciform shape where the Y-shaped S domain constitutes the central region of the RNA. From a structural point of view, it can be divided in twelve helices (1-12), four domains (I-IV) and four conserved motifs that represent the interaction sites for SRP proteins (Zwieb, 1985; Zwieb et al., 2005).

SRP9 and SRP14 possess an $\alpha \beta \beta \beta \alpha$ fold with topology similar to double strands RBPs, consisting of a three-stranded antiparallel $\beta$-sheet stacked against two $\alpha$-helices (Birse et al., 1997). They form a stable and obligate heterodimer that recognizes the RNA UGUNR motif, localized in the highly conserved 5' end of the Alu domain of the 7SL RNA, called the $\tau$-junction, which fold compactly as two helical stacks linked by U-turn (Weichenrieder et al., 2000). Consistent with its role in elongation arrest, the Alu domain binds in the ribosomal subunit interface (Halic et al., 2004).

SRP19 plays an essential role in the assembly of eukaryotic SRP. It is a single domain protein that belongs to the $\alpha \beta$ folding class of RBPs with a $\beta \alpha \beta \beta \alpha$ topology (Wild et al., 2001). The most basic region of SRP19 binds specifically to the tip of the GGAG tetraloop of helix 6 of the SRP RNA (Oubridge et al., 2002). This interaction clamps helices 6 and 8 together, inducing the typical closed S domain structure.

SRP54 is a key component in SRP signal sequence recognition and interaction with the ribosome and with the SRP receptor (Connolly and Gilmore, 1989). The protein contains three domains, named N, G and $\mathrm{M}$. The $\mathrm{N}$ and $\mathrm{G}$ domains form a functional unit called NG domain that confers GTPase activity during the SRP cycle and mediates SRP-SR interaction (Freymann et al., 1997). The hydrophobic C-terminal methionine-rich $\mathrm{M}$ domain has a helical fold and provides the RNA- and the signal sequence-binding sites (Keenan et al., 1998; Batey et al., 2000).

SRP68 and SRP72 are the least characterized SRP proteins, in terms of structure and function. SRP68 and SRP72 form a stable heterodimer that is essential for SRP functions and is suggested to coordinate the action of the $\mathrm{S}$ and Alu domain, facilitating elongation arrest after signal sequence recognition (Siegel and Walter, 1988; Andreazzoli and Gerbi, 1991). These two largest SRP components bind to the central region of the 7SL SRP RNA, around the three way junction formed by helix 5, 6, 7, and 8, and both consist of a RNA-binding domain (RBD) and a proteinbinding domain (PBD) (Yin et al., 2007). SRP68 has a quite large RNA-binding domain located at the N-terminus (52-252 aa) and contains a glycine-rich region typical of other RBPs, however it is not required for RNA binding (Herz et al., 1990). The relatively small RNA-binding region of SRP72 shares a conserved Pfam motif and a cluster of positively charged amino acids (Iakhiaeva et al., 2010). SRP72 protein binding domain is composed of nine antiparallel $a$-helices arranged in a closed $a$-solenoid. The domain comprises four tetratricopeptide repeats (TPRs) that binds the SRP68 protein binding domain, located at its C-terminus, in a conserved TPR-groove (Becker et al., 2017). SRP68-RBD (52-252 a. a) is a tetratricopeptide-like module 
TABLE 1 | Noncanonical functions and binding partners of SRP components.

\begin{tabular}{|c|c|c|c|}
\hline SRP component(s) & Main noncanonical function(s) & $\begin{array}{c}\text { Accessory complexes and binding } \\
\text { partners }\end{array}$ & Key references \\
\hline \multirow[t]{5}{*}{ 7SL RNA } & HIV-1 virus-packaging & Gag, APOBEC3F, АРОВЕСЗG & Tian et al. (2007); Wang et al. (2007b); Wang et al. (2008a) \\
\hline & Inhibition of HBsAg expression & EDEM1 (?) & Wang et al. (2014) \\
\hline & Red blood cells metabolism & RBCs & Talhouarne and Gall (2018) \\
\hline & Cell-cell communication & Extracellular vesicles & Nabet et al. (2017) \\
\hline & Proliferative effect & 3'UTR TP53 mRNA, HuR & Abdelmohsen et al. (2014) \\
\hline \multirow[t]{2}{*}{ SRP9/14 } & Regulator of translation & Alu RNPs, $40 \mathrm{~S}$ ribosome & Bovia et al. (1995); Hasler and Strub (2006) \\
\hline & Stress response & SGs & Berger et al. (2014) \\
\hline SRP9, SRP54 & HIV-1 virus-host interaction & HIV-Rev & Naji et al. (2012) \\
\hline SRP14 & HIV-1 virus-host interaction & HIV-Gag & Engeland et al. (2014) \\
\hline SRP54 & Transcription factor & SLC6A3 & Zhao et al. (2018) \\
\hline \multirow[t]{4}{*}{ SRP68/72 } & Transcription factor & $\mathrm{H} 4$ & Li et al. (2012) \\
\hline & Histone networks & $\mathrm{H} 1$ & Kalashnikova et al. (2013); Zhang et al. (2016) \\
\hline & Targeting of nucleolin (?) & Cell-surface nucleolin complex & Krust et al. (2011); Destouches et al. (2012) \\
\hline & HIV-1 virus-host interaction & Staufen1-RNP & Milev et al. (2012) \\
\hline \multirow[t]{2}{*}{ SRP68 } & Piggyback recruitment (?) & CASC-3 EJC-RNP complex & Mabin et al. (2018) \\
\hline & Stress response Piggyback recruitment (?) & TRAPPC2-SGs & Zappa et al. (2019) \\
\hline SRP72 & Apoptosis regulation & Caspases (?) & Utz et al. (1998) \\
\hline
\end{tabular}

composed of 7 antiparallel $\alpha$-helices and an extended loop region. SRP68 binding bends the RNA S domain and inserts an $\alpha$-helical arginine-rich motif (ARM) into the major groove (Grotwinkel et al., 2014).

A more recent cryo-EM structure (PDB 6FRK) describes the mammalian translating ribosome in complex with SRP and SR in a conformation preceding signal sequence delivery. The structure was determinated at 4.5 to $10 \AA$ resolution and allows to observe the architecture of the entire mammalian SRP-SR-RNC complex (Kobayashi et al., 2018).

\section{NONCANONICAL FUNCTIONS OF SRP AND ACCESSORY BINDING PARTNERS}

SRP components were first identified as integral part of the SRP machinery, however they have been implicated in regulation of many cellular processes, including gene expression, viral infection, apoptosis and stress response (Table 1).

SRP proteins and RNA have a dynamic spatiotemporal distribution in response to different cell signals. They switch between assembling into SRP complex and acting by themselves independently from the SRP upon interaction with a multitude of binding partners. The nature of SRP binding partners and their interaction dictates their additional biological functions (Table 1). An early study has identified the 7SL RNA in an RNP complex with one protein that was not part of the SRP complex (Avanesov, 1988). The protein was not further characterized, but it had a molecular weight of $80-85 \mathrm{kDa}$, which differs from the SRP proteins. More recently, 7SL RNA has been found in red blood cells (RBCs) and exosomes, reinforcing the hypothesis that 7SL RNA may be a dynamic component of new RNPs (Nabet et al., 2017; Talhouarne and Gall, 2018).

SRP9/14 can exist as free heterodimer localized predominantly in the cytoplasm in 20-fold excess over the SRP complex, or be part of different RNPs, suggesting additional functions outside the SRP cycle (Bovia et al., 1995).

Performing a dynamic choreography, SRP68/72 heterodimer is either involved in protein targeting associated with the SRP complex or involved in histone-binding activity, transcription regulation and potentially other chromatin-related functions. The binding of SRP68/72 to H4 was the first evidence for SRP transcriptional regulation functions ( $\mathrm{Li}$ et al., 2012), since then a transcription factor role was reported also for SRP54, expanding the picture of SRP-gene regulation (Zhao et al., 2018).

\section{SRP and Virus-Host Interactions}

SRP RNA was initially believed to serve as a scaffold for the six SRP proteins to bind onto it. Now, 7SL RNA is found to be a dynamic component of SRP involved in a wide repertoire of biological pathways, especially in virus-host responses (Elvekrog and Walter, 2015). To date 7SL RNA is the most abundant nontRNA species found in all retroviruses whose RNA contents has been determined (Brameier et al., 2013; Eckwahl et al., 2016). Different studies showed that 7SL RNA is selectively encapsulated into retroviruses, including Moloney murine leukemia virus (MuLV) (Duesberg and Robinson, 1966), Rous sarcoma virus (RSV) (Bishop et al., 1970), Feline infectious leukemia virus (FeLV) (Brian et al., 1975), Visna virus (Lin and Thormar, 1971), Equine infectious anemia virus (EIAV) (Cheevers et al., 1977) and HIV-1 (Onafuwa-Nuga et al., 2006).

Packaging of 7SL RNA has been extensively studied in HIV-1 where it is encapsulated in a 6-fold excess to the genomic viral RNA (T. Wang et al., 2007). The mechanism of selective packaging of 7SL RNA into HIV-1 virions was elucidated by Tian and Didierlaurent. The 7SL RNA is mainly associated with viral core structures and Gag protein via its RNA-binding nucleocapsid (NC) domain (Tian et al., 2007; Didierlaurent et al., 2011). The proposed model consists of different regions of Gag interacting with multiple domains of 7SL RNA suggesting 

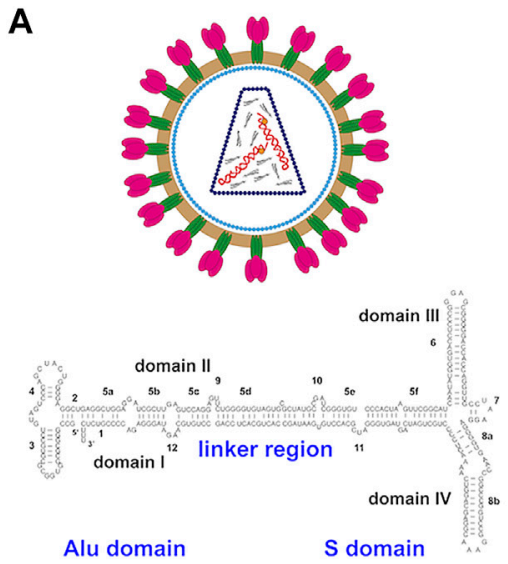

B

Alu114

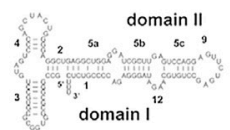

C

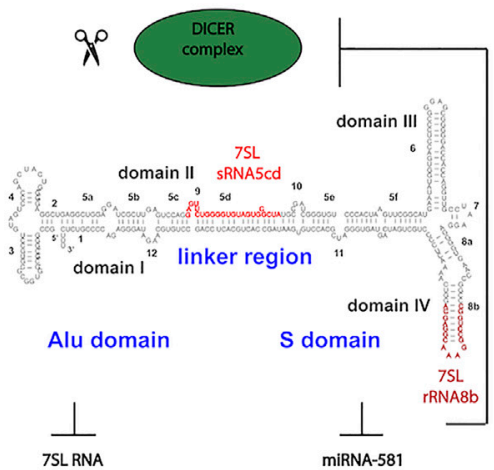

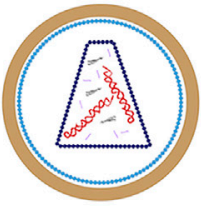


D

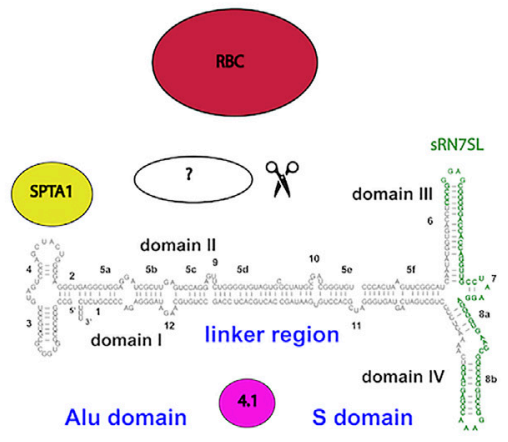

FIGURE 2 | Functional endonuclease processing of 7SL RNA in HIV-1 particles and RBCs (A) Trans-acting packaging determinants of 7SL RNA during HIV-1 packing. HIV-1 mature and virus-like particles (VLPs) retained intact 7SL RNA in NC-positive VPLs (Gag-NC domain is shown as orange dots). In NC-negative VPLs, 7SL RNA is retained mainly as an endoribonucleolytic fragment of $111 \mathrm{nt}$, named 7SL remnant (7SLrem) (B) The cis-acting determinants of 7SL packaging by HIV-1. Schematics of the Alu (Alu114) and the S domain (S114) derivatives capable of mediating packaging of 7SL RNA (C) 7SL RNA processing by Dicer in fragments sRNA5cd and sRNA8b which repress SRP complex formation and the expression of HBV surface antigen (HBsAg) (D) Enrichment for 7SL RNA and its fragment sRN7SL in an RBC RNP containing SPTA1 and protein 4.1.

that it may play a role in retroviral assembly by guiding Gag to sites of assembly or by facilitating Gag multimerization. During HIV-1 virus assembly, 7SL RNA interacts with two cytidine deaminases APOBEC3 (A3G and A3F) to enhance their packaging into HIV-1 virions, however, this finding remains controversial (Khan et al., 2007; Bach et al., 2008; Wang et al., 2008b). Future studies are needed to clarify the nature and function of the interaction between 7SL RNA and A3G/A3F, with particular emphasis on their ability for precise HIV-1 targeting and viral inhibition.

Trans-acting packaging factors have also been identified to interact with 7SL RNA during HIV-1 packing (Keene et al., 2010). HIV-1 virus-like particles (VLPs) retained 7SL RNA mainly as an endoribonucleolytic fragment of $111 \mathrm{nt}$, named 7SL remnant (7SLrem) (Figure 2A). The presence of 7SLrem correlated with the absence of the NC domain of Gag in VLPs while intact 7SL RNA was present in NC-positive VPLs, indicating that the NC domain may protect 7SL RNA from processing and degradation. The $5^{\prime}$ - and $3^{\prime}$-end of 7SLrem map to an unpaired loop in the full-length 7SL RNA, implying that an unidentified single-stranded endonuclease is responsible for its processing.

The cis-acting determinants of 7SL packaging by HIV-1 have been identified via exogenously expressed 7SL RNA mutants (Keene and Telesnitsky, 2012). Both Alu (Alu114 nt) and S domains (S114 nt) of 7SL RNA were able to mediate packaging independently (Figure 2B). Endogenous 7SL RNA 
and Alu domain were packaged through a competitive mechanism while the S domain was packaged efficiently via a separated additive mechanism. Interestingly, S114 resembles the 7SLrem fragment, while Alu114 corresponds to the murine 7SL derivative B1 (Onafuwa-Nuga et al., 2005).

The SRP proteins are also involved in the virus-host response. SRP14 has been identified in a proteomic analysis as one of the top 50 proteins interacting with Gag (Engeland et al., 2014). SRP14 levels are up-regulated after expression of the HIV-1 Tat protein, a trans-activator involved in binding to the viral long terminal repeat (LTR) (Jarboui et al., 2012). Further evidence of SRP14 involvement in virus-host interactions comes from a porcine orthologue in which knockdown of SRP14 by siRNAs inhibited the replication of the small RNA from Porcine reproductive and respiratory syndrome virus (PRRSV) (Zhao et al., 2017).

SRP9 and SRP54 interact with the HIV-1 Rev, a viral protein that plays a key role in the late phase of virus replication (Naji et al., 2012). Moreover, the Srp9 was identified among 10 genes which expression was reduced in astrocytes upon HIV-1 infection (Su et al., 2003).

Overexpression of SRP19 was associated with the depletion of the antiviral host protein $\mathrm{A} 3 \mathrm{G}$ from processing bodies ( $\mathrm{P}$ bodies), through the impair of 7SL RNA incorporation into virions, but did not affect its HIV-1 virion incorporation and A3F localization (Izumi et al., 2013). This data suggests that the association of A3G with $\mathrm{P}$ bodies may be dependent on the presence of 7SL RNA.

In HIV-1 infected cells, SRP68 and SRP72 have been found in cytosolic RNP complexes. These HIV-1 RNPs contain the genomic viral RNA, four viral proteins (Gag, Pol, Env, Nef), the double strand RNA-binding protein Staufen1 and other proteins involved in splicing, metabolism and cell traffic (Milev et al., 2012). During viral infection, HIV-1 protease cleaves SRP72 at amino acid residues A519-L520, within the cleavage site DVEA $\downarrow$ LENS (Impens et al., 2012). While the role of the proteolytic processing of SRP72 is not known, the finding reinforces the idea that modulation of protein translation during infection is probably achieved by proteolytic processing of additional host factors.

\section{SL RNA: Dicer, miRNAs and RBCs}

Several ncRNAs are spliced and/or processed into smaller products. 7SL RNA has been reported to be processed into multiples fragments with different regulatory functions. Dicer, a double strand endonuclease involved in miRNAs biogenesis, can process a minor portion of the cellular 7SL RNA pool into fragments of different lengths ranging from 20 to 200 nucleotides (Figure 2C) (Ren et al., 2012). Part of the Dicer-processed 7SL RNA fragments function as dominant-negative regulators of the full-length 7SL RNA, interfering with the formation of SRP complex and inhibiting ER-mediated protein secretion (Ren et al., 2013). A second biological function for Dicer-processed 7SL RNA fragments involves inhibition of miRNA-581 ability to stimulate Hepatitis B virus (HBV) surface antigen (HBsAg) expression (Wang et al., 2014). Interestingly, miRNA-581 targets Dicer expression through translation inhibition, suggesting the existence of a feedback loop between the intracellular levels of 7SL RNA, Dicer and its target miRNAs. The precise mechanism of processed 7SL RNA in inhibiting HBsAg expression remains unknown but it is likely to be mediated by endoplasmic reticulum degradationenhancing alpha-mannosidase-like protein 1 (EDEM1), a downstream target of miRNA-581.

Recently, 7SL RNA was identified as an abundant component of RBCs of human, mouse and Xenopus (Talhouarne and Gall, 2018). The enrichment for 7SL RNA in RBCs is probably due to selective retention during $\mathrm{RBC}$ maturation considering that mammalian RBCs lack nuclei and hence do not transcribe RNA. In mammalian RBCs, 7SL RNA is associated with a number of cytoskeletal and membrane-binding proteins, such as spectrin $a$ (SPTA1) and protein 4.1 (Figure 2D). RBCs can contain a short noncoding RNA of 68 nt called sRN7SL, derived from the $S$ domain of 7SL RNA. Production and accumulation of sRN7SL in RBCs is possibly mediated by an unidentified endonuclease. Interestingly, the sequence of sRN7SL overlaps with 7SLrem found in HIV-1 VLPs, suggesting that the $\mathrm{S}$ domain of 7SL RNA may carry multiple functions that could be regulated by post-transcriptional processing. A future challenge would be to characterize and understand the roles of other 7SL RNA post-transcriptional modifications. Focusing on how RNA processing contributes to SRP RNA localization and dynamics at the subcellular level would expand its increasing number of cellular functions.

\section{Alu Domain: Modulator of Translation and Stress Response}

The SRP Alu domain encompasses the $5^{\prime}$ - and $3^{\prime}$ - end of the 7SL RNA forming the Alu motif and the heterodimer SRP9/14. In addition to its role in translation control, as it arrests translation elongation upon SRP binding to translating ribosome, this domain is crucial for transcription, maturation, localization and transport of 7SL RNA (Siegel and Walter, 1988; Lakkaraju et al., 2008).

SRP9 and SRP14 form a stable heterodimer that can exist free in the cell or bound to the 7SL RNA with high specificity. The heterodimer can bind to a variety of small cytoplasmic ncRNAs structurally and phylogenetically related to the Alu motif of SRP RNA forming an assortment of Alu RNPs (Figure 3A) (Strub and Walter, 1990; Bovia et al., 1995; Chang et al., 1996; Bovia et al., 1997). Alu RNPs inhibit polysome formation through targeting SRP9/14 to a functional site in the $40 \mathrm{~S}$ ribosomal subunits, interfering with $48 \mathrm{~S}$ complex formation and translation initiation (Figure 3B) (Chu et al., 1998; Hasler and Strub, 2006). They inhibit translation of cellular mRNAs, as well as, viral IRES-mRNAs, modulating the translational output in response to stress and viral infection (Ivanova et al., 2015).

One of the many Alu-like RNAs that SRP9/14 binds with high affinity is the brain cytoplasmic 200 RNA (BC200 RNA) (Bovia et al., 1997; Kremerskothen et al., 1998). BC200 is specifically expressed in neurons localizing at somatodendritic region and in a number of tumors such as lung and breast carcinomas (Cheng et al., 1997; Kuryshev et al., 2001). BC200 exists as an 11.4 S RNP complex bound to SRP9/14 that acts as a regulator of decentralized translation in neuronal dendrites 


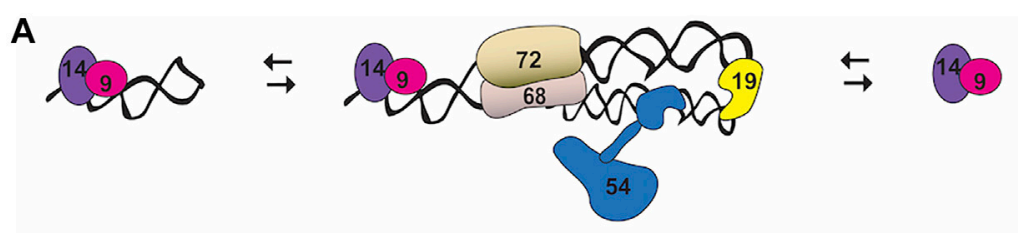

B
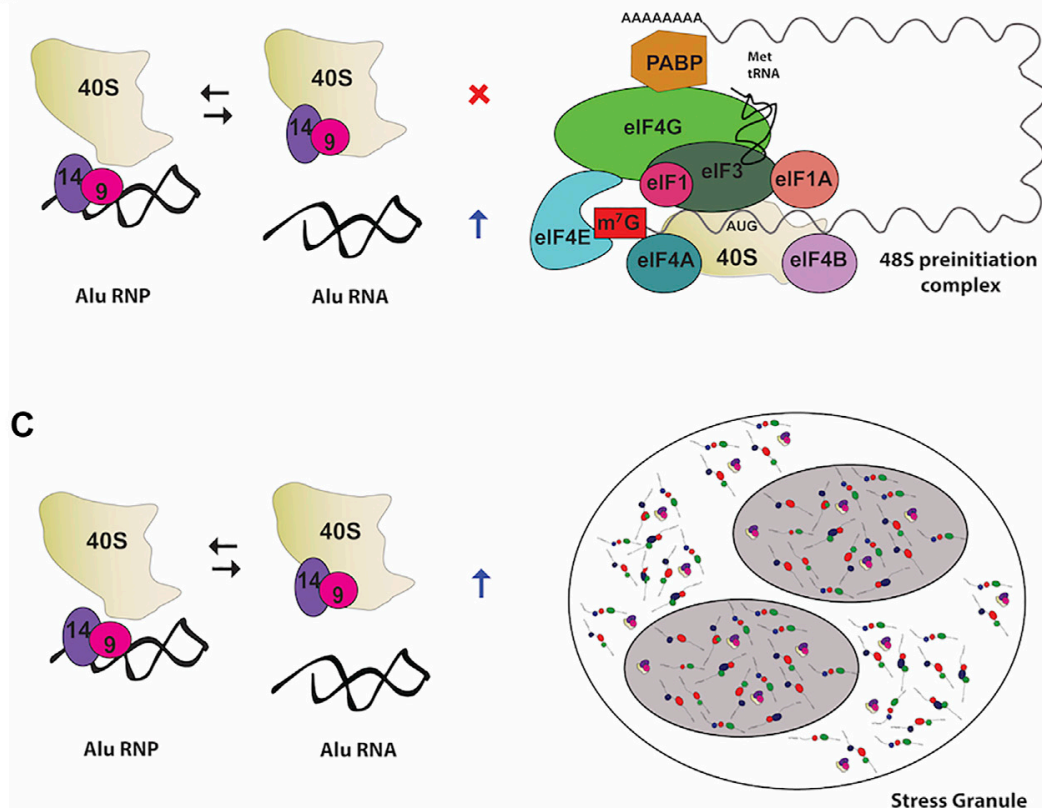

FIGURE 3 |Noncanonical functions of the heterodimer SRP9/14 (A) In primate cells, SRP9/14 exists as part of the SRP complex, as well as free protein and in RNP complexes with 7SL RNA-derivatives RNA, such as Alu RNA (B) Role of Alu RNP in regulating translation. Alu RNPs interfere with the formation of 48 S preinitiation complex by SRP9/14 binding to the ribosomal subunit 40 S. On the other hand, free Alu RNA stimulates translation by sequestering SRP9/14 (C) Role of Alu RNP in stress granules (SGs) assembly. SRP9/14 localizes to SGs through binding with the ribosomal subunit 40 S. Binding of SRP9/14 to 40 S and Alu RNA is mutually exclusive.

(Kremerskothen et al., 1998). Not only the inhibitory activity of BC200 RNAs in translation is enhanced by SRP9/14 but these SRP components are involved in stabilization and nuclear export of BC200.

SRP9/14 can be found in stress granules (SG) in response to stress (Figure 3C) (Berger et al., 2014). SG are very dynamic cytoplasmic structures composed of $40 \mathrm{~S}$ ribosomal subunits, translation initiation factors, mRNAs, RBPs and other signaling molecules. The expression level of the SRP9/14 determines the size and the number of SG-positive cells due to their involvement in formation and disassembly of SG upon binding to the $40 \mathrm{~S}$ ribosomal subunit (Berger et al., 2014). The mutually exclusive binding of SRP9/14 onto the Alu RNA and 40S regulates stress response by controlling SG levels. During stress recovery the concentration of cytoplasmic Alu RNA increases and promotes disassembly of SG by sequestering SRP9/14 (Berger et al., 2014).

Future studies should address the functional effect of SRP9/14 during cellular stress responses to human physiology and diseases.

Interestingly, SG and neuronal granules share many components, with BC200 involved in dendritic transport of
mRNA granules in neurons, suggesting that SRP9/14 may be involved in a more generic conserved mechanism of mRNP compartmentalization (Zalfa et al., 2005; Cao et al., 2006).

Large-scale identification and characterization of other SRP9/ 14-RNP complexes would be beneficial in unveiling more SRPindependent functions associated with this heterodimer. The analysis of the proteome and transcriptome associated with SRP9/14 could shed light on the mechanism underlying the recruitment of these components.

\section{The Heterodimer SRP68/72: Transcription Regulation and Histone Networks}

SRP68 and SRP72 form a stable heterodimer that assembles into the pre-SRP complex in the nucleus and is necessary for export to the cytoplasm (Grosshans et al., 2001). SRP68/72 was reported to bind chromatin and regulate transcription in an SRP independent manner (Li et al., 2012). Upon interaction with the tail of histone $\mathrm{H} 4$ in a methylation-sensitive manner, SRP68/72 regulates several gene expression indicating its role and interaction with other cellular components outside the protein synthesis cycle. 
A
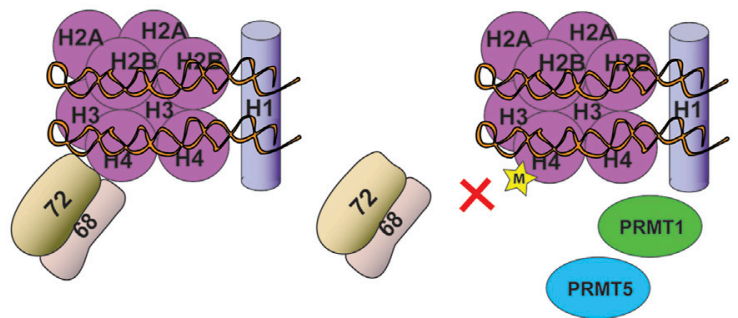

C

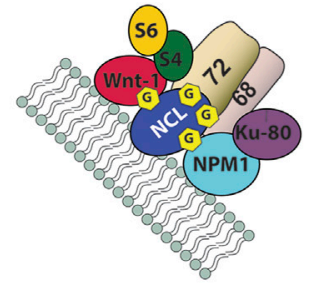

$x$

B

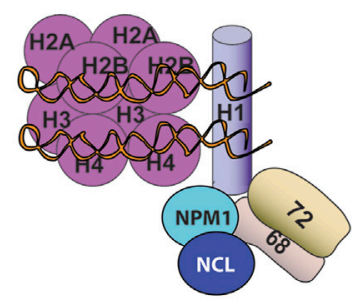

D

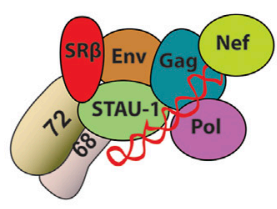

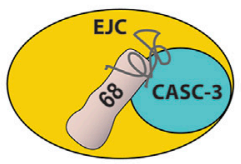

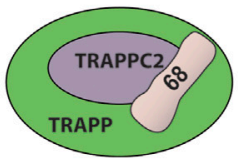

FIGURE 4 | Noncanonical function of the heterodimer SRP68/72 (A) SRP68/72 binds the tail of H4. Dimethylation of H4 by PRMT1 and PRMT5 causes SRP68/72 chromatin dissociation and shuttle in the cytoplasm (B) SRP68/72 binds C-terminal domain of $\mathrm{H} 1$ linker histone (C) SRP68/72 heterodimer was identified in different RNPs. It was found associated with cell-surface nucleolin (NCL) in a highly stable 500-kDa protein complex including several proteins (left) and in Staufen1-RNP complex (right), including four viral proteins (Gag, Env, Pol, Nef), the viral RNA (shown in red) and more than 200 other proteins (D) SRP68 was found associated to CASC-3 and TRAPPC2, respectively in EJC and TRAPP particles. Depicture of interactions in complexes are schematic only.

SRP68/72 can only bind to non-methylated or monomethylated H4. The post-translational marks H4R3me2a and H4R3me2s by the protein arginine methyltransferases (PRMT1 and PRMT5) have an inhibitory effect on SRP68/72-H4 tail binding (Figure 4A). Consistently, exogenous expression of PRMT1 and PRMT5 results in the dissociation of SRP68/72 from the chromatin and its export to the cytoplasm.

SRP68 and SRP72 proteins can transcriptionally activate a promoter-driver luciferase reporter, indicating for the first time a transcriptional regulation function for the SRP (Li et al., 2012). This activity was mapped into their protein-binding domain, corresponding to the C-terminus of SRP68 and the N-terminus of SRP72. ChIP-seq experiments reported that SRP68 binds genes involved in cell adhesion, cytoskeletal organization, DNA catabolism and apoptosis. Knockdown of SRP68 differentially affected the expression of its associated target genes, suggesting a context-dependent transcriptional function for SRP68. Future directions should focus on the transcriptional activity of SRP72, including the identification of genes that bind to SRP72, as well as the genes affected by SRP72 levels.

Two proteomic studies focused on characterizing the interaction network of $\mathrm{H} 1$ linker histones identified SRP68 and SRP72 as possible binding partners (Figure 4B) (Kalashnikova et al., 2013; Zhang et al., 2016). The H1 linker histones are a family of chromatin-associated DNA-binding proteins that function by stabilizing nucleosome structures and condensed states of chromatin (Woodcock et al., 2006). The majority of H1-binding proteins are components of the nucleolus, suggesting that SRP68/72 and H1 interaction happens in this cellular compartment. SRP68/72 can bind to at least three different variants of $\mathrm{H} 1$ (H1.1, H1.2, and $\mathrm{H} 1 . \mathrm{X})$ throughout the cell cycle, which may contribute to dynamically regulate linker histones. The SRP68-H1 interaction is mediated by the C-terminal domain of $\mathrm{H} 1$, an intrinsically disordered domain, however no structural information regarding SRP and histone interactions is available ( $\mathrm{Lu}$ et al., 2009). Currently the mechanism and the functional nature of the interaction between SRP68/72 and histones, such as $\mathrm{H1}$ and H4, have not yet been fully elucidated and further links between SRP68/72 and histones need to be unveiled.

\section{The Heterodimer SRP68/72: Multiple Noncanonical Binding Partners}

SRP68/72 heterodimer associates with cell-surface nucleolin in a stable $500-\mathrm{kDa}$ protein complex that includes proteins involved in cancer progression, such as nucleophosmin (NPM1), Wnt-1, the antigen $\mathrm{Ku} 80$ and $\mathrm{C} 1 \mathrm{q}-\mathrm{R}$, as well as the ribosomal proteins $\mathrm{S} 4$ and S6 (Figure 4C) (Krust et al., 2011; Destouches et al., 2012). Nucleolin is a multifunctional DNA-, RNA- and protein-binding protein that shuttles between different cellular compartments (Ginisty et al., 1999). At the cell surface, nucleolin serves as anchoring site for several ligands involved in cell proliferation, apoptosis, angiogenesis and as a low affinity receptor for HIV-1. Surface expressed nucleolin is glycosylated and constantly induced in tumor cells, as well as, activated endothelial cells 
and has been validated as a novel target in anticancer therapy (Srivastava and Pollard, 1999). The role of the association of SRP68/72 with cell-surface nucleolin is still unknown but these findings may indicate that SRP68/72 can coordinate the active translocation of nucleolin toward the plasma membrane or that nucleolin can regulate the nucleocytoplasmic shuttle of SRP68/72. Noteworthy, nucleolin and nucleophosmin are two histone chaperones, associated with both core and linker histones. Considering the link between SRP68/72 and histones, it is possible to envisage that SRP68/72 interaction with histones could be regulated by a nuclear binding partner, such as nucleolin and nucleophosmin. In addition, Ku80 and nucleolin are important autoantigens in patients with systemic lupus erythematosus and other systematic autoimmune disorders, suggesting a potential implication of SRP68/72 associated with the $500-\mathrm{kDa}$ complex in autoimmune diseases. Finally, in HIV-1 infected cells SRP68/72 and the SRP receptor SR $\beta$ have been found associated with nucleolin in Staufen1-RNP (Figure 4C), indicating that nucleolin and SRP68/72 interaction has a wider role in multiple RNPs (Milev et al., 2012). Nucleolin seems to be a key mediator in modulating SRP68/72 noncanonical functions and could be a potential candidate involved in shuttling this SRP heterodimer inside the cells.

Recently, SRP68 has been identified as a component of CASC3-containing exon junction RNP complex (EJC) through a weak RNA-interaction (Mabin et al., 2018) and as a binding partner of the TRAnsport Protein Particle complex subunit 2 (TRAPPC2), a trafficking complex localized in perinuclear granular structures (Figure 4D) (Zappa et al., 2019).

Although the roles of SRP68 in these multimolecular complexes remain to be defined, SRP68 could be involved in the recruitment of CASC3 and TRAPPC2 by a "piggyback" mechanism involving interaction with RNA, RBPs and RNPs components of EJC and SGs, respectively.

Identification of more noncanonical binding partners that can bind SRP68/72 and the functional and structural characterization of these interactions would clarify the different biological roles of SRP68/72 and its interplay with other RNPs. However, the instability and insolubility of SRP68/72 causes the purification of these proteins to remain challenging, contributing to the lack of crystallographic structural information of full-length proteins, to date. Moreover, the transient and highly dynamic nature of many RNPs makes structure determination a more arduous task.

\section{SRP72 and Apoptosis}

Post-translational modifications of proteins have been proposed by LeFeber to be essential to the development of autoantibodies and autoimmune diseases, leading to the hypothesis that modifications of autoantigens during apoptosis can cause the development of autoantibodies upon bypassing normal mechanism of tolerance (Lefeber et al., 1984; Utz and Anderson, 1998; Utz et al., 1998). For instance, Lupus autoantigens such as Ro, La and the U1-70 kDa proteins have been shown to localize to cell surface apoptotic blebs following UV-irradiation (Casciola-Rosen et al., 1994). SRP autoantigens have been identified as constituents of membranebound blebs on the surface of apoptotic cells, the ideal location for presentation to the immune system (Figure 5A). SRP components were found as constituents of discrete small cell surface apoptotic blebs $(\approx 1.4 \mu \mathrm{m}$ in diameter), including the ribonucleoprotein autoantigen Ro, calreticulin and the ER luminal marker BiP, in epidermal keratinocytes after UVB irradiation (Casciola-Rosen and Rosen, 1997).

The first direct evidence of the involvement of the SRP in apoptosis and the description of post-translational modifications of the SRP autoantigen complex was reported in 1998 by Utz and colleagues (Utz et al., 1998). Using sera from patients with different autoimmune diseases, SRP72 was the only SRP component identified to be phosphorylated and cleaved during apoptosis (Figure 5B) (Utz et al., 1998). Despite the fact that SRP72 proteolytic cleavage can be prevented with caspase inhibitors, the caspase responsible for cleaving SRP72 remains unknown. SRP72 has a group III caspases putative cleavage site $\left({ }_{614} \mathrm{SELD} / \mathrm{A}_{618}\right)$ followed by highly conserved serine residues that produces a $6 \mathrm{kDaC}$-terminal phosphorylated peptide. The fate of the phosphorylated peptide remains unknown, however selective phosphorylation of SRP72 suggests that a serine kinase and/or a phosphatase regulates SRP72 levels.

Caspase-mediated cleavage of certain proteins during apoptosis has been shown to contribute directly to the apoptotic phenotype (Rudel and Bokoch, 1997). Currently it is still unknown whether phosphorylation or caspase-mediated cleavage of SRP72 contributes to the production of autoantibodies reactive with components of the SRP complex. The cleavage of SRP72 may play a critical role when apoptosis is induced by envelop virus, since many viral proteins pass through the ER, suggesting that SRP72 cleavage may protect neighboring cells by preventing viral replication and shedding.

In addition, a correlation between SRP and TNF related apoptosis inducing ligand (TRAIL)-death- receptor pathway reinforces the involvement of SRP in apoptosis and reveals a mechanistic relationship between protein trafficking and cell death signaling (Ren et al., 2004). TRAIL signaling plays a main role in tumor immune-surveillance by inducing selectively apoptosis in cancer cells and sensitivity of cancer cells to TRAIL correlates with the surface level of death receptors DR4 and DR5 (Zhang et al., 1999). A pro-apoptotic role of SRP is necessary for DR4-mediated apoptosis and sensitivity in cancer cells. Silencing SRP54 or SRP72 by RNAi inhibits DR4-mediated apoptosis by decreasing DR4 cell surface localization and blocking the TRAIL cascade at the apical point, before procaspase- 8 processing. Interestingly, SRP silencing had no effect in DR5 cell surface localization, indicating a specificity in regulating DR4-pathway instead of DR5 and other TNF receptors.

Future studies are needed to unravel the mechanistic details of SRP involvement in apoptosis. A starting point would be the characterization of the cellular pathway that leads to SRP72 phosphorylation and cleavage and the relation between SRP and extrinsic signaling through death receptors.

\section{SRP AND DISEASES}

With multiple functionalities within cells, deregulation of SRP expression results in diseases and malignancy, suggesting that 

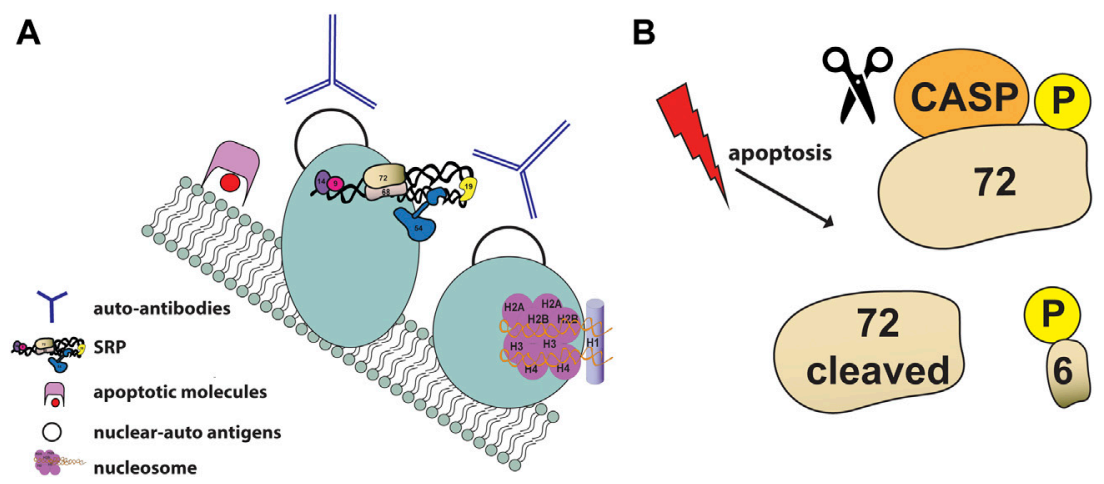

FIGURE 5 | SRP and apoptosis (A) Schematic illustration of SRP autoantigens as constituents of membrane-bound blebs (shown as light blue circles) on the surface of apoptotic cells. Apoptotic blebs display many nuclear auto-antigens (shown as black empty circles) such as nucleosomes (shown in purple) and accumulate apoptotic molecules (shown in pink and red). Auto-reactive antibodies (shown as blue Y) generated against nuclear antigens are showns around the blebs (B) SRP72 is phosphorylated and cleaved during apoptosis. The proteolytic cleavage of SRP72 by caspases produces a $6 \mathrm{kDaC}$-terminal phosphorylated peptide of unknown fate.

TABLE 2 | Diseases and biomarkers associated with SRP subunits.

\begin{tabular}{|c|c|c|c|c|c|}
\hline $\begin{array}{l}\text { SRP } \\
\text { component }\end{array}$ & Autoimmune diseases & Expression in cancer & Genetic diseases & $\begin{array}{l}\text { Targets and } \\
\text { biomarker }\end{array}$ & References \\
\hline 7SL RNA & & $\begin{array}{l}\uparrow \text { liver, lung, breast and } \\
\text { stomach cancer }\end{array}$ & & oncogene & $\begin{array}{l}\text { White (2004); Abdelmohsen } \\
\text { et al. (2014) }\end{array}$ \\
\hline SRP9 & & $\begin{array}{l}\uparrow \text { metastatic human prostate } \\
\text { cancer, hepatocellular and } \\
\text { colorectal adenocarcinoma }\end{array}$ & & $\begin{array}{l}\text { gastric cancer } \\
\text { RFS in multiple } \\
\text { sclerosis }\end{array}$ & $\begin{array}{l}\text { Liu et al. (2007); Rho et al. } \\
\text { (2008); Ye et al. (2020) }\end{array}$ \\
\hline SRP14 & & $\begin{array}{l}\uparrow \text { metastatic human prostate } \\
\text { cancer and KRAS-positive } \\
\text { cells }\end{array}$ & & gastric cancer & Kundu et al. (2012) \\
\hline SRP19 & $\begin{array}{l}\text { Idiopathic inflammatory myopathies } \\
\text { (IIM), such as dermatomyositis, }\end{array}$ & $\downarrow$ bladder cancer cells & & $\begin{array}{l}\text { colon cancer that } \\
\text { harbour APC loss }\end{array}$ & $\begin{array}{l}\text { Tsai et al. (2014); Rosenbluh } \\
\text { et al. (2016) }\end{array}$ \\
\hline SRP54 & $\begin{array}{l}\text { polymyositis and necrotizing } \\
\text { autoimmune myositis }\end{array}$ & $\begin{array}{l}\uparrow \text { metastatic human prostate } \\
\text { cancer cells }\end{array}$ & $\begin{array}{l}\text { Congenital neutropenia } \\
\text { with Shwachman- } \\
\text { Diamond-like phenotype }\end{array}$ & $\begin{array}{l}\text { kidney transplant } \\
\text { outcome }\end{array}$ & $\begin{array}{l}\text { Srivastava et al., (2015); } \\
\text { Bellanne-Chantelot et al. } \\
\text { (2018) }\end{array}$ \\
\hline SRP68 & & $\begin{array}{l}\uparrow \text { breast and bladder cancer } \\
\text { cells }\end{array}$ & Congenital neutropenia & RF radiation & Zhang et al. (2013) \\
\hline SRP72 & & $\begin{array}{l}\uparrow \text { breast, thyroid and prostate } \\
\text { cancer cells }\end{array}$ & $\begin{array}{l}\text { Aplastic anemia, } \\
\text { myelodysplasia }\end{array}$ & $\begin{array}{l}\text { radiosensitivity } \\
\text { thyroid oncogene } \\
\text { drug-induced } \\
\text { hepatotoxicity }\end{array}$ & $\begin{array}{l}\text { Tiwana et al. (2015); Chai } \\
\text { et al. (2016); Vatakuti et al. } \\
\text { (2016) }\end{array}$ \\
\hline
\end{tabular}

controlling the expression levels of SRP components is key to normal cellular function (Table 2). SRP autoantibodies have been found in the serum of patients with a wide range of myopathies. SRP components have been involved in noncanonical pathways, cancer and other diseases, suggesting a new perspective in using SRP components as biomarkers. Multiple proteomic and genomic studies report alteration in gene expression of SRP components, however only 7SL RNA has been shown to have a direct role in cancer progression.

To date, mutations associated with genetic diseases have been reported for three components of the SRP. SRP72, SRP54 and SRP68 display mutations associated with bone marrow failure, opening a new window into the pathophysiology of SRP and genetic diseases.

\section{SRP Autoantibodies and Autoimmune Diseases}

SRP has been implicated in the progression of different idiopathic inflammatory myopathies (IIM), such as dermatomyositis, polymyositis and necrotizing autoimmune myositis. IIM are chronic autoimmune muscle diseases characterized by muscle weakness, inflammation in skeletal muscle tissues and by the presence of autoantibodies against specific cellular components, 
particularly RNP complexes (Findlay et al., 2015; Lundberg et al., 2016).

Autoantibodies targeting SRP are subjects of considerable clinical interest and were first described in 1986 (Reeves et al., 1986). Human antibodies against SRP immunoprecipitated the 7SL RNA and all the SRP proteins. Among all components of SRP, SRP54 is considered the main antigenic target of anti-SRP antibodies (Targoff et al., 1990) with antibodies against SRP54 found in patients with severe myopathies and Lupus-type autoimmune diseases (Miller et al., 2002; Hengstman et al., 2006). Specific SRP54 antibody inhibitory effect is on translocation upon interference with signal sequence binding and SRP receptor interaction, most likely by steric hindrance (Romisch et al., 2006).

The mechanism of anti-SRP associated myopathy is mediated in a complement-dependent antibody as suggested by SRP colocalization on the cell surface with $\mathrm{C} 3 \mathrm{c}$, the activated product of the central component of the complement system C3 (RojanaUdomsart et al., 2013). At the cell surface, SRP can bind to antiSRP antibodies forming antigen-antibody complexes that activate the membrane attack complex C5b-9. Surface redistribution of intracellular ribonuclear antigens, such as Ro and $\mathrm{La}$, has been shown to occur in skin cells undergoing apoptosis, however the mechanism responsible to the presence of SRP in cell surface remains unknown (Casciola-Rosen et al., 1994; Herrera-Esparza et al., 2006).

Whether or not SRP is associated with a specific form of immune-mediate myopathy is still under debate. Anti-SRP autoantibodies were specific for severe polymyositis, necrotizing myopathy and sometimes detected in patients with other autoimmune syndromes such as rheumatoid arthritis, inflammatory bowel disease and systematic sclerosis (Miller et al., 2002; Kao et al., 2004).

The presence of anti-SRP autoantibodies is associated with a unique spectrum of clinical phenotype called "the anti-SRP syndrome" with significance in diagnosis, management and prognosis of the disease (Targoff, 2000). Based on clinical observation, the presence of anti-SRP antibodies correlates with a broad acute onset of severe features, such as progressive proximal weakness, dysphagia and resistance to standard treatments. Anti-SRP positive patients have a rarity or absence of foci of mononuclear inflammatory cells (Miller et al., 2002).

Anti-SRP autoantibodies were found in patients with necrotising myopathy with a rapid progressive course and severe disability (Hengstman et al., 2006). In inflammatory myopathy, anti-SRP antibodies are associated with different clinical courses and histological presentation, including severe limb weakness, muscle atrophy and poor neurological outcomes (Suzuki et al., 2015). Anti-SRP19 antibodies were present in skeletal muscle tissues of patients with autoimmune necrotizing myopathy (Wang et al., 2016). SRP19 antibodies expression was found mainly in necrotic myofibers, the stroma cells and the surrounding small blood vessels. Interestingly, the presence of anti-SRP19 antibodies in non-necrotic myofibers suggests a possible role of SRP19 in the early stages of the disease.
The most common cause of death in IIM patients are cardiovascular manifestations and cancer (Danko et al., 2004; Garcia-De La Torre, 2015). An association between anti-SRP and cardiac disease has been proposed with anti-SRP antibodies found in cases of cardiac involvement in the form of arrhythmia and cardiomyopathy (Hirakata et al., 1992). A comparative study showed that anti-SRP positive patients with polymyositis had cardiac symptoms that included edema, dyspnea on exertion, and chest pain, but the cardiac involvement was considered statistically nonsignificant (Hengstman et al., 2006). More recently, in juvenile IIM, the presence of anti-SRP was associated with more frequent abnormal ECG and by echocardiography (Rider et al., 2013). Three single nucleotide polymorphisms (SNPs) located in the SRP54 antisense gene were found to be associated with cardiovascular diseases in patients with systemic lupus erythematosus but not with rheumatoid arthritis (Leonard et al., 2018), however, further studies are necessary to clarify the risk of cardiac involvement in SRP-myopathy.

Cancer can occur in $20 \%$ of patients with IIM, especially during dermatomyositis (Zahr and Baer, 2011). Cancers were detected in 5-17\% of patients with anti-SRP myopathy, however no significant difference was found in clinical features between SRP-cancer and SRP-cancer free patients (Allenbach et al., 2016; Kadoya et al., 2017).

\section{SRP Components as Biomarkers in Cancer}

7SL RNA is up-regulated in several cancer cells and its silencing is correlated with reduction in cell proliferation (White, 2004). Analysis of 80 tumor specimens representing 19 types of cancer revealed that 7SL RNA is abnormally abundant in every tumor analyzed, including liver, lung, breast and stomach cancer (W. Chen et al., 1997). The proliferative effect of the 7SL RNA is due by its interaction with the $3^{\prime}$ untranslated region ( $3^{\prime}$ UTR) of TP53 mRNA, which encodes for the tumor suppressor p53 (Abdelmohsen et al., 2014). This interaction reduces p53 translation preventing the recruitment of the RNA-binding protein Human antigen $\mathrm{R}(\mathrm{HuR})$ to TP53 mRNA. Silencing of 7SL RNA increases p53 translation through recruitment of $\mathrm{HuR}$, suggesting a mechanism in which 7SL and HuR compete for binding TP53 $3^{\prime}$ UTR. Transcription of 7SL RNA is repressed by the tumor suppressor FOXP3, contributing to tumor growth inhibition (Yang et al., 2016). ChIP analysis showed that FOXP3 directly binds to the 7SL RNA promoter regions, through Forkead/HNF-3 domain DNA binding sites. Repression of 7SL RNA by FOXP3 promotes the expression of the downstream target p53 protein, indicating a feedback loop between FOXP3, p53 and 7SL.

In breast cancer, the 7SL RNA has been found in extracellular vesicle (EV)-mediated cell transfer (Nabet et al., 2017). EVs are mobile membrane-limited vesicles, which contains proteins, RNA and lipids derived from the cytoplasm of their donor cell and can transfer their contents intercellular, providing a mechanism of cell-cell communication (Gyorgy et al., 2011). Since 7SL RNA and its correlated RN7SL1 pseudo-genes were found in stromal cell-derived EVs, it could be implied a potential role for 7SL RNA in acting as a damage-associated molecular 
pattern (DAMP) in the crosstalk between stromal cells and breast cancer cells. Transfer of 7SL RNA by activated stromal EVs to adjacent triple-negative breast cancer cells stimulates anti-viral signaling, resulting in enhanced tumor growth and a malignant phenotype (Nabet et al., 2017). Specifically, stromal 7SL RNA stimulates the viral RNA pattern recognition receptor (PRR) RIG-I, resulting in STAT1 activation and interferon-stimulated genes (ISG) induction. Specific bind of 7SL RNA to the C-terminal domain (CTD) of RIG-I is mediated by the presence of the common RNA viral structural motif $5^{\prime}$ triphosphate ( $\left.5^{\prime} \mathrm{ppp}\right)$ at its end.

Multiple studies analysing differential gene and protein expression profile have identified SRP proteins associated with cancer or other diseases. SRP9/14 have been involved in cancer development. SRP9 mRNA was found up-regulated in hepatocellular carcinoma via gene array studies (Liu et al., 2007) while a proteomic analysis has shown it was overexpressed in patients with colorectal adenocarcinoma (Rho et al., 2008), suggesting SRP9 as a candidate biomarker for colon cancers. Two recurrent nonsynonymous RNA editing events that recode the amino acid sequence of SRP9 were observed in colorectal cancer and in primary breast cancer (Shah et al., 2009; Lee et al., 2017). Additionally, SRP9 protein was found overexpressed in small lymphocytic lymphoma (SLL) (Rolland et al., 2011). SRP14 expression was enhanced in cell lines positive for the KRAS-variant, an oncogene frequently mutated in various types of cancer (Kundu et al., 2012). The heterodimer SRP9/14 levels increased in the serum of the $\mathrm{H} 22$ hepatoma-bearing mice and its expression reduced by the antitumoral Scutellaria barbata polisaccharides (Li et al., 2019).

SRP19 has been associated with colon and gastric cancer. Srp19 gene is in close proximity to the tumor suppressor adenomatous polyposis coli (APC) gene, which is often deleted in ß-catenin-active cancers (Joslyn et al., 1991). SRP19 mRNA and protein levels were lowered in cell lines harboring APC deletion and shRNA targeting SRP19 inhibited proliferation of cells, confirming Srp19 as a CYCLOPOS gene in colon cancer with APC loss (Rosenbluh et al., 2016). Srp19 gene has been associated with gastric cancer, with a significantly lower copy number compared to healthy patients and may serve as a potential novel biomarker to identify high-risk individuals (Tsai et al., 2014). Regulation of the expression of SRP genes and proteins in liver and colon cancer remains to be elucidated; however, alterations in the expression levels of SRP9/14 and SRP19 indicate a key role for SRP in gastro-related cancer.

Srp68 and Srp19 genes were among 516 genes differentially expressed in bladder cancer and reported to be up-regulated and down-regulated respectively (Zekri et al., 2015). Srp68 and Srp72 genes were identified as potential nuclear LIM-only protein 4 (LMO4) - target genes in human breast cancer cells (N. Wang et al., 2007).

Few evidences of association between SRP and prostate cancer were also reported. SRP9, SRP14 and SRP54 were overexpressed in metastatic prostate cancer cells treated with curcumin, an ER stress-mediated pro-apoptotic and antitumoral molecule extracted from the turmeric rhizome (Rivera et al., 2017). In prostate cancer, Srp72 gene was identified as a downstream target of the cancer biomarker TWIST, associated with cancer invasion and metastasis (Lyu et al., 2017). Srp72 gene was a recurrent mutated cancer-driving gene in thyroid cancer (Chai et al., 2016). Srp72 is overexpressed and hypomethylated which suggests it may have oncogenic function in thyroid cancer by altering the methylation status. A deletion in Srp72 gene (4q22.3) was also implicated in copy number variation in thyroid cancer, suggesting that this gene may contribute to the formation and progression of thyroid cancer in various ways (Chai et al., 2016).

\section{SRP Role in Other Diseases and Noncanonical Pathways}

SRP genes and proteins were found specifically involved in a multitude of diseases and pathways. Interestingly, a comparative proteomic study of inflammatory vs. angiogenic activated endothelial cells identified all the SRP components to be overexpressed upon interleukin 1 beta (IL1B) and vascular endothelial growth factor (VEGF) treatment (Mohr et al., 2017) suggesting a role of SRP in angiogenesis and inflammatory pathways. Srp9, Srp14 and Srp54 genes were upregulated in patients with thyroid-associated ophthalmopathy (TAO), suggesting that SRP might play a role in the development of TAO (Zhao et al., 2015).

A transcriptomic approach using human precision-cut liver slices, identified Srp72 among with different ER stress genes as a marker phenotype of drug-induced hepatotoxicity, confirming the involvement of ER stress in cholestasis and liver toxicity (Chen et al., 2014; Vatakuti et al., 2016). Recently, SRP72 was identified as a radiosensitizer and has been proposed as a modulator of radiosensitivity in mammalian cells (Tiwana et al., 2015). SRP72 depletion was associated with a decreased radiosurvival after irradiation and correlated with a delayed G2/ $\mathrm{M}$ cell arrest, elevated level of apoptosis and unfolded protein response (Prevo et al., 2017). Due to healthy cells also being affected by SRP72 depletion, a drug inhibition of SRP72 is unlikely to be a useful strategy for radiotherapy treatment, but SRP72 levels can be a biomarker for radiosensitivity. Interestingly, an independent study reported that SRP68 expression decreased significantly, suggesting it as a biomarker, in human lens epithelial cells exposed to radiofrequency radiation (Zhang et al., 2013).

Srp19 gene was found up-regulated in patients with KashinBeck disease $(\mathrm{KBD})$ and $\mathrm{KBD}$ accompanied with dental fluorosis (DF) (Zhang et al., 2018). In another study, Srp19 gene was identified as a nitric oxide-sensitive gene and found downregulated in human monocytic cells after exposure of nitric oxide (Turpaev et al., 2010). SRP54 protein was identify among the top-ranking five non-invasive biomarkers that can accurately predict kidney transplant outcome and its downregulation presenting a detrimental profile common for both rejection and injuries (Srivastava et al., 2015).

A more recent function of SRP in brain diseases has emerged recently. Srp54 gene expression was strongly down-regulated in response to anti-inflammatory and anti-depressant drugs (Ulrich-Merzenich et al., 2012) and a single nucleotide 
polymorphism (SNP) in Srp54 has been associated with bipolar affective disorder (Baum et al., 2008). Moreover, in neurons, SRP54 was reported as a novel dopaminergic transcription factor which significantly enhances the promoter activity of the dopamine transporter (DAT) gene SLC6A3 (Zhao et al., 2018).

Srp9 was identified as a febrile seizure (FS) susceptibility gene and its overexpression found to increase FS susceptibility through ERdependent synthesis and trafficking of membrane proteins, such as glutamate receptors (Hessel et al., 2014). Furthermore, Srp9 gene was reported to contribute to neuroticism, a high-order personality trait (Ohi et al., 2017). It was found to be intensively enriched in brain and associated with the glutamate receptor activity network. Recently, Srp9 gene was found to be part of a five-gene signature proposed as a novel marker tool to predict the relapse-free survival (RFS) in patients with multiple sclerosis (Ye et al., 2020).

The role of SRP19 and SRP54 in neuronal diseases, such as bipolar affective disorder and neuroticism, need to be eluciated and warrant future investigation. However, it can be postulated that the glutamate network might be a key target of SRP in the brain.

Finally, a transcriptome profile study revealed that transcripts related to translation, including the cytoplasmic non-coding RNA 7SL, were enriched in the axons of motoneurons, indicating for the presence of the protein secretion machinery in axons (Briese et al., 2016).

\section{SRP Genetic Diseases and Trans-splicing Events}

Autosomal-dominant mutations in SRP72 were identified in the pathophysiology of aplastic anemia (AA) and myelodysplasia (MDS), two forms of bone marrow failure that are associated with an increased risk of hematologic malignancy (Kirwan et al., 2012; Galaverna et al., 2018). Two different heterozygous SRP72 mutations were found in two families: a missense mutation in exon $6(\mathrm{R} 207 \mathrm{H})$, near the middle of the sixth TPR domain, and a deletion in its RNA-binding domain (T355deletion). The mutated SRP72 protein localizes incorrectly within the cell, with impaired ability to assemble onto the SRP complex. These finding support a link between a defect in protein translocation and AA/MDS.

The molecular role of SRP in the hematopoietic system and its involvement in aberrant haematopoiesis is currently unknown. Recently, a Srp72 deficient mouse model was developed to characterize the impact of heterozygous loss of Srp72 on murine haematopoiesis (D'altri et al., 2019). In contrast to the severe phenotype observed in two families, heterozygous loss of Srp72 in mice was associated only to a mild haematological phenotype. Despite this, modulation of SRP72 levels influenced the transcriptional down-regulation of key hematopoietic cytokines and receptors.

Autosomal dominant mutations in SRP54 were reported to cause syndromic congenital neutropenia $(\mathrm{CN})$ with a Shwachman-Diamond-like phenotype (SDS), a rare inherited bone marrow failure disorder (Carapito et al., 2017; BellanneChantelot et al., 2018; Goldberg et al., 2020). Four different mutations were identified (T115A, T115deletion, T117deletion, G226E) from SDS patients, all of them affecting highly conserved amino acids within the G-domain of SRP54. The T115A, T115deletion and T117deletion impair SRP54 GTPase activity function, while the G226E affects SR receptor binding, leading to ER stress and autophagy (Juaire et al., 2021).

SRP54 mutations are not restricted to SDS patients and could be involved in the generic mechanism of neutropenia. In fact, mutations in SRP54 are the second most common cause of severe inherited neutropenia in the French Congenital Neutropenia Registry (Oyarbide and Corey, 2018).

At the beginning of 2021, the first in vivo model of SRP54 deficiency in zebrafish indicated that SRP54 is critical for the development of multiple tissues and its mutations impair neutrophil differentiation by hampering the unconventional splicing of the transcription factor XBP1 (Schürch et al., 2021).

Recently, SRP68 has been implicated as well in a sporadic case of severe CN (Schmaltz-Panneau et al., 2021). A large intronic homozygous deletion of exon 1 (c.184+2T >C) of SRP68 gene was found responsible to trigger an ER stress resulting in an increased P53-dependet apoptosis of granulocytic precursors and neutrophils.

Alternative splicing involving SRP19 and APC genes has been reported (Kinzler et al., 1991; Horii et al., 1993) with the intergenic trans-splicing being controlled in a tissue-specific manner, but the role of the chimera product remains unknown. Interestingly, another trans splicing event involving SRP72 and Calcium/calmodulin-dependent protein kinase II (CaM II) produced a chimera isoform of CaM II kinase called $\gamma \mathrm{SRP}$ in human islets of Langerhans (Breen and Ashcroft, 1997). The $\gamma \mathrm{SRP}$ isoform retains most of the catalytic properties of CaM II, however its functional role still needs to be identified.

Alternative spliced transcript variants encoding multiple isoforms have been observed for SRP68 gene. Three pseudogenes of Srp68 gene are located within the SmithMagenis syndrome (SMS) region on chromosome 17 (Park et al., 2002). This region is believed to mediate nonallelic homologous recombination, resulting in both SMS deletions and reciprocal duplications (K.-S. Chen et al., 1997).

\section{SRP as a Drug Target}

Recently, the bacterial SRP was proposed as a potential target for developing a new class of antibiotics (Faoro et al., 2018; Ghosh et al., 2018). However, to date, the human SRP has not been explored directly as a potential target for drug discovery.

A number of inhibitors/drugs such as aflatoxin B1 (AFB1), leptomycin B and ivermectin have been shown to either interact with SRP components or inhibit its nuclear export/import process (Alavian et al., 2004; Wagstaff et al., 2012). The hepatocarcinogen AFB1 has been shown to interact with components of the SRP Alu domain and to interfere with the formation of functional SRP S domain (Singh et al., 2005; Singh et al., 2006). The mechanism of action of AFB1 on SRP is selective to bind SRP9/14 and to inhibit the expression of SRP54 and SRP72.

Currently, the first and only anticancer drug reported to target the SRP is TAS-103, a quinoline derivative that displays antitumor activity in murine and human models (Utsugi et al., 1997; Byl et al., 1999; Ohyama et al., 1999). TAS-103 specifically binds to SRP54 disrupting SRP formation and reduces the 
expression of SRP14 and SRP19 (Yoshida et al., 2008). Functional studies are needed to investigate the interaction of SRP and TAS103 and the role of SRP disruption in cancer for drug discovery, indicating a much larger range of drug targeting potential toward the SRP components.

Due to the SRP multifunctionality and its vital role in cellular processes, there is a potential to develop therapies targeting specifically some of the SPR components noncanonical functions. From a structural point of view, the identification and characterization of the binding interface of accessory proteins and SRP components could be exploited with small molecules or RNA analogues to target specific interactions in the cell that could be potentially linked to diseases. Protein-protein interactions are challenging targets, as they can overlap with the SRP-RNA binding sites, however, some of these binding interfaces may turn into prospective targets for drug design if they do not interfere with the canonical function of SRP. For the therapeutical point of view, detailed studies focusing on the individual interaction interface between SRP components and their noncanonical counterparts are needed to drive the drug discovery process.

In particular, the 7SL RNA is an interesting target for the development of new anticancer drugs. The recent identified interaction between the 7SL RNA and TP53 mRNA could be targeted for the treatment of cancers with reduced p53 levels. Promising, the influence of 7SL on p53 expression is likely independent of its function as part of the SRP (Abdelmohsen et al., 2014).

Whether 7SL also influences the expression of other proteins involved in proliferation of cancer cells remains to be investigated. Future research topic should focus in elucidating the function of the 7SL RNA in cancer, investigating its tissuespecific interaction with other RNAs and the possibility of targeting these RNA-RNA interactions. Finally, a murine model system of 7SL RNA would be beneficial to evaluate the efficacy and safety of different treatments for cancer.

Furthermore, targeting the noncanonical role of SRP9/14 in SGs formation and disassembly could be a potential therapeutic strategy for the treatment of many human diseases where SGs are mainly involved, such as pathogenesis of neurodegenerative diseases, viral infection, aging and cancers (Wang et al., 2020). For instance, a promising field to explore would be the identification of small molecules that target SRP9/14 in SGs and modulate its Alu-RNA binding activity.

Another interesting noncanonical function that could be targeted is the interaction of nucleolin with the heterodimer SRP68/72 for cancer therapies and autoimmune diseases. Further studies will be able to reveal the nature of their interaction and how are these interactions regulated, providing a starting point for drug design.

Targeting SRP72 post-translational modification could be used for the treatment of patients with autoimmune diseases and/or to prevent some envelop virus replication. Future work is warranted to identify the caspase responsible for cleaving SRP72 and the kinase and phosphatase that regulate SRP72 levels.

SRP components could also be targeted to develop anti-viral therapies. For instance, considering the implication of some SRP components in HIV-1 infection, their targeting could be investigated for new antiretroviral therapies. Further research is needed to define better the role of the 7SL RNA and its fragments in retrovirus assembly. Functional and structural studies are warranted to explore the interaction of SRP components, such as SRP9, SRP14 and SRP54, with HIV-1 proteins, such as Gag and Rev. Some of the interactions between the SRP components and different viruses are expected to be similar which will facilitate the drug development process.

\section{CONCLUSION}

The SRP components are extensively involved in a large range of cellular processes other than its original role in protein translocation, underlying a dynamic plasticity of SRP RNPs in cells. Considering the complex new scenario of SRP and its noncanonical functions, this RNP can no longer be categorized solely under its own canonical function.

Future studies focusing on noncanonical functions of SRP components are urgently needed to elucidate the role of SRP in signaling cascades that influence vital cellular processes and cancer development. For instance, the identification of novel interacting partners and coactivators are warranted to illustrate the role of SRP in these pathways.

Characterizing the spatial-temporal dynamic composition of SRP RNPs during different cell processes and diseases could reveal new functions for SRP components that have not been explored yet. While unveiling the proteome and transcriptome associated with SRP could identify new cellular partners and functions under physiological cell processes.

Whether therapies will be tailored toward the 7SL RNA that has been extensively linked to cancer and malignancy, or to block some specific interactions of the SRP proteins with other cellular partners, there are more noncanonical functions to be uncovered and explored yet. A new unexplored SRP world is emerging, with several "SRPrizes" which play a significant role in diseases and dynamic cellular processes.

\section{AUTHOR CONTRIBUTIONS}

CF and SFA conceived the review focus, conducted literature review, summarized, and finalized the manuscript. All authors approved final version of manuscript.

\section{FUNDING}

This work was supported by The University of Sydney internal funds to SFA.

\section{ACKNOWLEDGMENTS}

We would like to thank David Tomlinson for the critical reading of the manuscript. 


\section{REFERENCES}

Abdelmohsen, K., Panda, A. C., Kang, M.-J., Guo, R., Kim, J., Grammatikakis, I., et al. (2014). 7SL RNA Represses P53 Translation by Competing with HuR. Nucleic Acids Res. 42, 10099-10111. doi:10.1093/nar/gku686

Akopian, D., Shen, K., Zhang, X., and Shan, S.-o. (2013). Signal Recognition Particle: an Essential Protein-Targeting Machine. Annu. Rev. Biochem. 82, 693-721. doi:10.1146/annurev-biochem-072711-164732

Alavian, C. N., Ritland Politz, J. C., Lewandowski, L. B., Powers, C. M., and Pederson, T. (2004). Nuclear Export of Signal Recognition Particle RNA in Mammalian Cells. Biochem. Biophysical Res. Commun. 313, 351-355. doi:10. 1016/j.bbrc.2003.11.126

Allenbach, Y., Keraen, J., Bouvier, A.-m., Jooste, V., Champtiaux, N., Hervier, B., et al. (2016). High Risk of Cancer in Autoimmune Necrotizing Myopathies: Usefulness of Myositis Specific Antibody. Brain 139, 2131-2135. doi:10.1093/ brain/aww054

Andreazzoli, M., and Gerbi, S. A. (1991). Changes in 7SL RNA Conformation during the Signal Recognition Particle Cycle. EMBO J. 10, 767-777. doi:10. 1002/j.1460-2075.1991.tb08008.x

Avanesov, A. (1988). [Isolation and Characterization of a New Class of Cytoplasmic RNP-Particles from Rabbit Reticulocytes Containing 7SL RNA]. Biokhimiia 53, 1912-1919 .

Bach, D., Peddi, S., Mangeat, B., Lakkaraju, A., Strub, K., and Trono, D. (2008). Characterization of APOBEC3G Binding to 7SL RNA. Retrovirology 5, 54. doi:10.1186/1742-4690-5-54

Batey, R. T., Rambo, R. P., Lucast, L., Rha, B., and Doudna, J. A. (2000). Crystal Structure of the Ribonucleoprotein Core of the Signal Recognition Particle. Science 287, 1232-1239. doi:10.1126/science.287.5456.1232

Baum, A. E., Akula, N., Cabanero, M., Cardona, I., Corona, W., Klemens, B., et al. (2008). A Genome-wide Association Study Implicates Diacylglycerol Kinase Eta (DGKH) and Several Other Genes in the Etiology of Bipolar Disorder. Mol. Psychiatry 13, 197-207. doi:10.1038/sj.mp.4002012

Becker, M. M. M., Lapouge, K., Segnitz, B., Wild, K., and Sinning, I. (2017). Structures of Human SRP72 Complexes Provide Insights into SRP RNA Remodeling and Ribosome Interaction. Nucleic Acids Res. 45, 470-481. doi:10.1093/nar/gkw1124

Bellanne-Chantelot, C., Schmaltz-Panneau, B., Marty, C., Fenneteau, O., Callebaut, I., Clauin, S., et al. (2018). Mutations in SRP54 Gene Cause Severe Congenital Neutropenia as Well as Shwachman-Diamond-like Syndrome. Blood 132, 1318-1331. doi:10.1182/blood-2017-12-820308

Berger, A., Ivanova, E., Gareau, C., Scherrer, A., Mazroui, R., and Strub, K. (2014). Direct Binding of the Alu Binding Protein Dimer SRP9/14 to 40S Ribosomal Subunits Promotes Stress Granule Formation and Is Regulated by Alu RNA. Nucleic Acids Res. 42, 11203-11217. doi:10.1093/nar/gku822

Birse, D. E. A., Kapp, U., Strub, K., Cusack, S., and Åberg, A. (1997). The Crystal Structure of the Signal Recognition Particle Alu RNA Binding Heterodimer, SRP9/14. EMBO J. 16, 3757-3766. doi:10.1093/emboj/16.13.3757

Bishop, J. M., Levinson, W. E., Sullivan, D., Fanshier, L., Quintrell, N., and Jackson, J. (1970). The Low Molecular Weight RNAs of Rous Sarcoma Virus. Virology 42, 927-937. doi:10.1016/0042-6822(70)90341-7

Bovia, F., Fornallaz, M., Leffers, H., and Strub, K. (1995). The SRP9/14 Subunit of the Signal Recognition Particle (SRP) Is Present in More Than 20-fold Excess over SRP in Primate Cells and Exists Primarily Free but Also in Complex with Small Cytoplasmic Alu RNAs. Mol Bio Cell. 6, 471-484. doi:10.1091/mbc.6. 4.471

Bovia, F., Wolff, N., Ryser, S., and Strub, K. (1997). The SRP9/14 Subunit of the Human Signal Recognition Particle Binds to a Variety of Alu-like RNAs and with Higher Affinity Than its Mouse Homolog. Nucleic Acids Res. 25, 318-326. doi:10.1093/nar/25.2.318

Brameier, M., Ibing, W., Hofer, K., Montag, J., Stahl-Hennig, C., and Motzkus, D. (2013). Mapping the Small RNA Content of Simian Immunodeficiency Virions (SIV). PLoS One 8, e75063. doi:10.1371/journal.pone.0075063

Breen, M. A., and Ashcroft, S. J. H. (1997). A Truncated Isoform of Ca2+/ calmodulin-dependent Protein Kinase II Expressed in Human Islets of Langerhans May Result from Trans-splicing. FEBS Lett. 409, 375-379. doi:10.1016/s0014-5793(97)00555-3
Brian, D. A., Thomason, A. R., Rottman, F. M., and Velicer, L. F. (1975). Properties of Feline Leukemia Virus. III. Analysis of the RNA. J. Virol. 16, 535-545. doi:10. 1128/jvi.16.3.535-545.1975

Briese, M., Saal, L., Appenzeller, S., Moradi, M., Baluapuri, A., and Sendtner, M. (2016). Whole Transcriptome Profiling Reveals the RNA Content of Motor Axons. Nucleic Acids Res. 44, e33. doi:10.1093/nar/gkv1027

Byl, J. A., Fortune, J. M., Burden, D. A., Nitiss, J. L., Utsugi, T., Yamada, Y., et al. (1999). DNA Topoisomerases as Targets for the Anticancer Drug TAS-103: Primary Cellular Target and DNA Cleavage Enhancement. Biochemistry 38, 15573-15579. doi:10.1021/bi9917910

Cao, X., Yeo, G., Muotri, A. R., Kuwabara, T., and Gage, F. H. (2006). Noncoding RNAs in the Mammalian Central Nervous System. Annu. Rev. Neurosci. 29, 77-103. doi:10.1146/annurev.neuro.29.051605.112839

Carapito, R., Konantz, M., Paillard, C., Miao, Z., Pichot, A., Leduc, M. S., et al. (2017). Mutations in Signal Recognition Particle SRP54 Cause Syndromic Neutropenia with Shwachman-Diamond-like Features. J. Clin. Invest. 127, 4090-4103. doi:10.1172/jci92876

Casciola-Rosen, L. A., Anhalt, G., and Rosen, A. (1994). Autoantigens Targeted in Systemic Lupus Erythematosus Are Clustered in Two Populations of Surface Structures on Apoptotic Keratinocytes. J. Exp. Med. 179, 1317-1330. doi:10. 1084/jem.179.4.1317

Casciola-Rosen, L., and Rosen, A. (1997). Ultraviolet Light-Induced Keratinocyte Apoptosis: a Potential Mechanism for the Induction of Skin Lesions and Autoantibody Production in LE. Lupus 6, 175-180. doi:10.1177/ 096120339700600213

Chai, L., Li, J., and Lv, Z. (2016). An Integrated Analysis of Cancer Genes in Thyroid Cancer. Oncol. Rep. 35, 962-970. doi:10.3892/or.2015.4466

Chang, D., Hsu, K., and Maraia, R. J. (1996). Monomeric scAlu and Nascent Dimeric Alu RNAs Induced by Adenovirus Are Assembled into SRP9/14Containing RNPs in HeLa Cells. Nucleic Acids Res. 24, 4165-4170. doi:10.1093/ nar/24.21.4165

Cheevers, W. P., Archer, B. G., and Crawford, T. B. (1977). Characterization of RNA from Equine Infectious Anemia Virus. J. Virol. 24, 489-497. doi:10.1128/ jvi.24.2.489-497.1977

Chen, K.-S., Manian, P., Koeuth, T., Potocki, L., Zhao, Q., Chinault, A. C., et al. (1997a). Homologous Recombination of a Flanking Repeat Gene Cluster Is a Mechanism for a Common Contiguous Gene Deletion Syndrome. Nat. Genet. 17, 154-163. doi:10.1038/ng1097-154

Chen, S., Melchior, W. B., Jr., and Guo, L. (2014). Endoplasmic Reticulum Stress in Drug- and Environmental Toxicant-Induced Liver Toxicity. J. Environ. Sci. Health C 32, 83-104. doi:10.1080/10590501.2014.881648

Chen, W., Böcker, W., Brosius, J., and Tiedge, H. (1997b). Expression of Neural BC200 RNA in Human Tumours. J. Pathol. 183, 345-351. doi:10.1002/(sici) 1096-9896(199711)183:3<345::aid-path930>3.0.co;2-8

Cheng, J. G., Tiedge, H., and Brosius, J. (1997). Expression of Dendritic BC200 RNA, Component of a 11.4S Ribonucleoprotein Particle, Is Conserved in Humans and Simians. Neurosci. Lett. 224 (3), 206-210. doi:10.1016/s03043940(97)13471-1

Chu, W.-M., Ballard, R., Carpick, B. W., Williams, B. R. G., and Schmid, C. W. (1998). Potential Alu Function: Regulation of the Activity of Double-Stranded RNA-Activated Kinase PKR. Mol. Cel. Biol. 18, 58-68. doi:10.1128/mcb.18.1.58

Connolly, T., and Gilmore, R. (1989). The Signal Recognition Particle Receptor Mediates the GTP-dependent Displacement of SRP from the Signal Sequence of the Nascent Polypeptide. Cell 57, 599-610. doi:10.1016/0092-8674(89)90129-3

Connolly, T., Rapiejko, P., and Gilmore, R. (1991). Requirement of GTP Hydrolysis for Dissociation of the Signal Recognition Particle from its Receptor. Science 252, 1171-1173. doi:10.1126/science.252.5009.1171

Cross, B. C. S., Sinning, I., Luirink, J., and High, S. (2009). Delivering Proteins for Export from the Cytosol. Nat. Rev. Mol. Cel Biol 10, 255-264. doi:10.1038/ nrm 2657

D'altri, T., Schuster, M. B., Wenzel, A., and Porse, B. T. (2019). Heterozygous Loss of Srp72 in Mice Is Not Associated with Major Hematological Phenotypes. Eur. J. Haematol. 103, 319-328. doi:10.1111/ejh.13286

Dankó, K., Ponyi, A., Constantin, T., Borgulya, G., and Szegedi, G. (2004). LongTerm Survival of Patients with Idiopathic Inflammatory Myopathies According to Clinical Features. Medicine (Baltimore) 83, 35-42. doi:10.1097/01.md. $0000109755.65914 .5 \mathrm{e}$ 
Destouches, D., Huet, E., Sader, M., Frechault, S., Carpentier, G., Ayoul, F., et al. (2012). Multivalent Pseudopeptides Targeting Cell Surface Nucleoproteins Inhibit Cancer Cell Invasion through Tissue Inhibitor of Metalloproteinases 3 (TIMP-3) Release. J. Biol. Chem. 287, 43685-43693. doi:10.1074/jbc.m112. 380402

Didierlaurent, L., Racine, P. J., Houzet, L., Chamontin, C., Berkhout, B., and Mougel, M. (2011). Role of HIV-1 RNA and Protein Determinants for the Selective Packaging of Spliced and Unspliced Viral RNA and Host U6 and 7SL RNA in Virus Particles. Nucleic Acids Res. 39, 8915-8927. doi:10.1093/nar/ gkr577

Duesberg, P. H., and Robinson, W. S. (1966). Nucleic Acid and Proteins Isolated from the Rauscher Mouse Leukemia Virus (MLV). Proc. Natl. Acad. Sci. 55, 219-227. doi:10.1073/pnas.55.1.219

Eckwahl, M. J., Telesnitsky, A., and Wolin, S. L. (2016). Host RNA Packaging by Retroviruses: A Newly Synthesized Story. MBio 7-02015. e02025. doi:10.1128/ mbio.02025-15

Elvekrog, M. M., and Walter, P. (2015). Dynamics of Co-translational Protein Targeting. Curr. Opin. Chem. Biol. 29, 79-86. doi:10.1016/j.cbpa.2015.09.016

Engeland, C. E., Brown, N. P., Börner, K., Schümann, M., Krause, E., Kaderali, L., et al. (2014). Proteome Analysis of the HIV-1 Gag Interactome. Virology 460461, 194-206. doi:10.1016/j.virol.2014.04.038

Faoro, C., Wilkinson-White, L., Kwan, A. H., and Ataide, S. F. (2018). Discovery of Fragments that Target Key Interactions in the Signal Recognition Particle (SRP) as Potential Leads for a New Class of Antibiotics. PLoS One 13, e0200387. doi:10.1371/journal.pone.0200387

Findlay, A. R., Goyal, N. A., and Mozaffar, T. (2015). An Overview of Polymyositis and Dermatomyositis. Muscle Nerve 51, 638-656. doi:10.1002/mus.24566

Freymann, D. M., Keenan, R. J., Stroud, R. M., and Walter, P. (1997). Structure of the Conserved GTPase Domain of the Signal Recognition Particle. Nature 385, 361-364. doi:10.1038/385361a0

Galaverna, F., Ruggeri, A., and Locatelli, F. (2018). Myelodysplastic Syndromes in Children. Curr. Opin. Oncol. 30, 402-408. doi:10.1097/cco. 0000000000000488

Garcia-De La Torre, I. (2015). Clinical Usefulness of Autoantibodies in Idiopathic Inflammatory Myositis. Front. Immunol. 6, 331. doi:10.3389/fimmu.2015.00331

Ghosh, S., Saini, S., and Saraogi, I. (2018). Peptide Nucleic Acid Mediated Inhibition of the Bacterial Signal Recognition Particle. Chem. Commun. 54, 8257-8260. doi:10.1039/c8cc04715d

Ginisty, H., Sicard, H., Roger, B., and Bouvet, P. (1999). Structure and Functions of Nucleolin. J. Cel Sci 112 (Pt 6), 761-772. doi:10.1242/jcs.112.6.761

Goldberg, L., Simon, A. J., Rechavi, G., Lev, A., Barel, O., Kunik, V., et al. (2020). Congenital Neutropenia with Variable Clinical Presentation in Novel Mutation of the SRP54 Gene. Pediatr. Blood Cancer 67, e28237. doi:10.1002/pbc.28237

Grosshans, H., Deinert, K., Hurt, E., and Simos, G. (2001). Biogenesis of the Signal Recognition Particle (SRP) Involves Import of SRP Proteins into the Nucleolus, Assembly with the SRP-RNA, and Xpolp-Mediated Export. J. Cel Biol 153, 745-762. doi:10.1083/jcb.153.4.745

Grotwinkel, J. T., Wild, K., Segnitz, B., and Sinning, I. (2014). SRP RNA Remodeling by SRP68 Explains its Role in Protein Translocation. Science 344, 101-104. doi:10.1126/science.1249094

Gundelfinger, E. D., Krause, E., Melli, M., and Dobberstein, B. (1983). The Organization of the 7SL RNA in the Signal Recognition Particle. Nucl. Acids Res. 11, 7363-7374. doi:10.1093/nar/11.21.7363

György, B., Szabó, T. G., Pásztói, M., Pál, Z., Misják, P., Aradi, B., et al. (2011). Membrane Vesicles, Current State-Of-The-Art: Emerging Role of Extracellular Vesicles. Cell. Mol. Life Sci. 68, 2667-2688. doi:10.1007/ s00018-011-0689-3

Halic, M., Becker, T., Pool, M. R., Spahn, C. M. T., Grassucci, R. A., Frank, J., et al. (2004). Structure of the Signal Recognition Particle Interacting with the Elongation-Arrested Ribosome. Nature 427, 808-814. doi:10.1038/nature02342

Halic, M., Blau, M., Becker, T., Mielke, T., Pool, M. R., Wild, K., et al. (2006). Following the Signal Sequence from Ribosomal Tunnel Exit to Signal Recognition Particle. Nature 444, 507-511. doi:10.1038/nature05326

Hartl, F. U., Bracher, A., and Hayer-Hartl, M. (2011). Molecular Chaperones in Protein Folding and Proteostasis. Nature 475, 324-332. doi:10.1038/ nature 10317

Hasler, J., and Strub, K. (2006). Alu RNP and Alu RNA Regulate Translation Initiation In Vitro. Nucleic Acids Res. 34, 2374-2385. doi:10.1093/nar/gkl246
Hegde, R. S., and Keenan, R. J. (2011). Tail-anchored Membrane Protein Insertion into the Endoplasmic Reticulum. Nat. Rev. Mol. Cel Biol 12, 787-798. doi:10. $1038 / \mathrm{nrm} 3226$

Hengstman, G. J. D., Ter Laak, H. J., Vree Egberts, W. T. M., Lundberg, I. E., Moutsopoulos, H. M., Vencovsky, J., et al. (2006). Anti-signal Recognition Particle Autoantibodies: Marker of a Necrotising Myopathy. Ann. Rheum. Dis. 65, 1635-1638. doi:10.1136/ard.2006.052191

Herrera-Esparza, R., Villalobos, R., Bollain-y-Goytia, J.-J., Ramírez-Sandoval, R., Sánchez-Rodriguez, S. H., Pacheco-Tovar, G., et al. (2006). Apoptosis and Redistribution of the Ro Autoantigen in Balb/c Mouse like in Subacute Cutaneous Lupus Erythematosus. Clin. Develop. Immunol. 13, 163-166. doi:10.1080/17402520600876796

Herz, J., Flint, N., Stanley, K., Frank, R., and Dobberstein, B. (1990). The 68 kDa Protein of Signal Recognition Particle Contains a Glycine-Rich Region Also Found in Certain RNA-Binding Proteins. FEBS Lett. 276, 103-107. doi:10.1016/ 0014-5793(90)80518-n

Hessel, E. V. S., Wit, M., Wolterink-Donselaar, I. G., Karst, H., Graaff, E., Lith, H. A., et al. (2014). Identification of Srp9 as a Febrile Seizure Susceptibility Gene. Ann. Clin. Transl Neurol. 1, 239-250. doi:10.1002/acn3.48

Hirakata, M., Mimori, T., Akizuki, M., Craft, J., Hardin, J. A., and Homma, M. (1992). Autoantibodies to Small Nuclear and Cytoplasmic Ribonucleoproteins in Japanese Patients with Inflammatory Muscle Disease. Arthritis Rheum. 35, 449-456. doi:10.1002/art.1780350415

Horii, A., Nakatsuru, S., Ichii, S., Nagase, H., and Nakamura, Y. (1993). Multiple Forms of the APC Gene Transcripts and Their Tissue-specific Expression. Hum. Mol. Genet. 2, 283-287. doi:10.1093/hmg/2.3.283

Iakhiaeva, E., Iakhiaev, A., and Zwieb, C. (2010). Identification of amino acid residues in protein SRP72 required for binding to a kinked 5e motif of the human signal recognition particle RNA. BMC Mol. Biol. 11, 83. doi:10.1186/ 1471-2199-11-83

Impens, F., Timmerman, E., Staes, A., Moens, K., Ariën, K. K., Verhasselt, B., et al. (2012). A Catalogue of Putative HIV-1 Protease Host Cell Substrates. Biol. Chem. 393, 915-931. doi:10.1515/hsz-2012-0168

Ivanova, E., Berger, A., Scherrer, A., Alkalaeva, E., and Strub, K. (2015). Alu RNA Regulates the Cellular Pool of Active Ribosomes by Targeted Delivery of SRP9/ 14 to 40 S Subunits. Nucleic Acids Res. 43, 2874-2887. doi:10.1093/nar/gkv048

Izumi, T., Burdick, R., Shigemi, M., Plisov, S., Hu, W.-S., and Pathak, V. K. (2013). Mov10 and APOBEC3G Localization to Processing Bodies Is Not Required for Virion Incorporation and Antiviral Activity. J. Virol. 87, 11047-11062. doi:10. 1128/jvi.02070-13

Jarboui, M. A., Bidoia, C., Woods, E., Roe, B., Wynne, K., Elia, G., et al. (2012). Nucleolar Protein Trafficking in Response to HIV-1 Tat: Rewiring the Nucleolus. PLoS One 7, e48702. doi:10.1371/journal.pone.0048702

Joslyn, G., Carlson, M., Thliveris, A., Albertsen, H., Gelbert, L., Samowitz, W., et al. (1991). Identification of Deletion Mutations and Three New Genes at the Familial Polyposis Locus. Cell 66, 601-613. doi:10.1016/0092-8674(81)90022-2

Juaire, K. D., Lapouge, K., Becker, M. M. M., Kotova, I., Michelhans, M., Carapito, R., et al. (2021). Structural and Functional Impact of SRP54 Mutations Causing Severe Congenital Neutropenia. Structure 29, 15-28. doi:10.1016/j.str.2020. 09.008

Kadoya, M., Taira, K., Ikenaga, C., Uchio, N., Kubota, A., Mimori, T., et al. (2017). Evaluation for the Clinical Significance of Cancer-Association in Anti-SRP Antibody-Positive Myopathy. J. Neurol. Sci. 381, 470. doi:10.1016/j.jns.2017.08. 3534

Kalashnikova, A. A., Winkler, D. D., Mcbryant, S. J., Henderson, R. K., Herman, J. A., Deluca, J. G., et al. (2013). Linker Histone H1.0 Interacts with an Extensive Network of Proteins Found in the Nucleolus. Nucleic Acids Res. 41, 4026-4035. doi:10.1093/nar/gkt104

Kao, A. H., Lacomis, D., Lucas, M., Fertig, N., and Oddis, C. V. (2004). Anti-signal Recognition Particle Autoantibody in Patients with and Patients without Idiopathic Inflammatory Myopathy. Arthritis Rheum. 50, 209-215. doi:10. 1002/art.11484

Keenan, R. J., Freymann, D. M., Walter, P., and Stroud, R. M. (1998). Crystal Structure of the Signal Sequence Binding Subunit of the Signal Recognition Particle. Cell 94, 181-191. doi:10.1016/s0092-8674(00)81418-x

Keene, S. E., King, S. R., and Telesnitsky, A. (2010). 7SL RNA Is Retained in HIV-1 Minimal Virus-like Particles as an S-Domain Fragment. J Virol. 84, 9070-9077. doi:10.1128/jvi.00714-10 
Keene, S. E., and Telesnitsky, A. (2012). cis-Acting Determinants of 7SL RNA Packaging by HIV-1. J. Virol. 86, 7934-7942. doi:10.1128/jvi.00856-12

Khan, M. A., Goila-Gaur, R., Opi, S., Miyagi, E., Takeuchi, H., Kao, S., et al. (2007). Analysis of the Contribution of Cellular and Viral RNA to the Packaging of APOBEC3G into HIV-1 Virions. Retrovirology 4, 48. doi:10.1186/1742-46904-48

Kinzler, K., Nilbert, M., Su, L., Vogelstein, B., Bryan, T., Levy, D., et al. (1991). Identification of FAP Locus Genes from Chromosome 5q21. Science 253, 661-665.doi:10.1126/science.1651562

Kirwan, M., Walne, A. J., Plagnol, V., Velangi, M., Ho, A., Hossain, U., et al. (2012). Exome Sequencing Identifies Autosomal-Dominant SRP72 Mutations Associated with Familial Aplasia and Myelodysplasia. Am. J. Hum. Genet. 90, 888-892. doi:10.1016/j.ajhg.2012.03.020

Kobayashi, K., Jomaa, A., Lee, J. H., Chandrasekar, S., Boehringer, D., Shan, S. O., et al. (2018). Structure of a Prehandover Mammalian Ribosomal SRP.SRP Receptor Targeting Complex. Science 360, 323-327. doi:10.1126/science. aar7924

Kremerskothen, J., Zopf, D., Walter, P., Cheng, J. G., Nettermann, M., Niewerth, U., et al. (1998). Heterodimer SRP9/14 Is an Integral Part of the Neural BC200 RNP in Primate Brain. Neurosci. Lett. 245, 123-126. doi:10.1016/s03043940(98)00215-8

Krust, B., El Khoury, D., Nondier, I., Soundaramourty, C., and Hovanessian, A. G. (2011). Targeting Surface Nucleolin with Multivalent HB-19 and Related Nucant Pseudopeptides Results in Distinct Inhibitory Mechanisms Depending on the Malignant Tumor Cell Type. BMC Cancer 11, 333. doi:10.1186/1471-2407-11-333

Kundu, S. T., Nallur, S., Paranjape, T., Boeke, M., Weidhaas, J. B., and Slack, F. J. (2012). KRAS Alleles: the LCS6 3'UTR Variant and KRAS Coding Sequence Mutations in the NCI-60 Panel. Cell Cycle 11, 361-366. doi:10.4161/cc.11.2. 18794

Kuryshev, V. Y., Kremerskothen, J., Jurka, J., and Brosius, J. (2001). Birth of a Gene: Locus of Neuronal BC200 snmRNA in Three Prosimians and Human BC200 Pseudogenes as Archives of Change in the Anthropoidea Lineage. J. Mol. Biol. 309, 1049-1066. doi:10.1006/jmbi.2001.4725

Lakkaraju, A. K., Mary, C., Scherrer, A., Johnson, A. E., and Strub, K. (2008). SRP Keeps Polypeptides Translocation-Competent by Slowing Translation to Match Limiting ER-Targeting Sites. Cell 133, 440-451. doi:10.1016/j.cell.2008.02.049

Lee, S. H., Kim, H. P., Kang, J. K., Song, S. H., Han, S. W., and Kim, T. Y. (2017). Identification of Diverse Adenosine-To-Inosine RNA Editing Subtypes in Colorectal Cancer. Cancer Res. Treat. 49, 1077-1087. doi:10.4143/crt.2016.301

Lefeber, W. P., Norris, D. A., Ryan, S. R., Huff, J. C., Lee, L. A., Kubo, M., et al. (1984). Ultraviolet Light Induces Binding of Antibodies to Selected Nuclear Antigens on Cultured Human Keratinocytes. J. Clin. Invest. 74, 1545-1551. doi:10.1172/jci111569

Leonard, D., Svenungsson, E., Dahlqvist, J., Alexsson, A., Arlestig, L., Taylor, K. E., et al. (2018). Novel Gene Variants Associated with Cardiovascular Disease in Systemic Lupus Erythematosus and Rheumatoid Arthritis. Ann. Rheum. Dis. 77, 1063-1069. doi:10.1136/annrheumdis-2017-212614

Li, J., Zhou, F., Zhan, D., Gao, Q., Cui, N., Li, J., et al. (2012). A Novel Histone H4 Arginine 3 Methylation-Sensitive Histone H4 Binding Activity and Transcriptional Regulatory Function for Signal Recognition Particle Subunits SRP68 and SRP72. J. Biol. Chem. 287, 40641-40651. doi:10.1074/ jbc.m112.414284

Li, L., Xu, X., Wu, L., Zhu, H., He, Z., Zhang, B., et al. (2019). Scutellaria Barbata Polysaccharides Inhibit Tumor Growth and Affect the Serum Proteomic Profiling of Hepatoma H22bearing Mice. Mol. Med. Rep. 19. 2254-2262. doi:10.3892/mmr.2019.9862

Li, Y., and Tergaonkar, V. (2014). Noncanonical Functions of Telomerase: Implications in Telomerase-Targeted Cancer Therapies. Cancer Res. 74, 1639-1644. doi:10.1158/0008-5472.can-13-3568

Lin, F. H., and Thormar, H. (1971). Characterization of Ribonucleic Acid from Visna Virus. J. Virol. 7, 582-587. doi:10.1128/jvi.7.5.582-587.1971

Liu, Y., Zhu, X., Zhu, J., Liao, S., Tang, Q., Liu, K., et al. (2007). Identification of Differential Expression of Genes in Hepatocellular Carcinoma by Suppression Subtractive Hybridization Combined cDNA Microarray. Oncol. Rep. 18, 943-951.

Lu, X., Hamkalo, B., Parseghian, M. H., and Hansen, J. C. (2009). Chromatin Condensing Functions of the Linker Histone C-Terminal Domain Are
Mediated by Specific Amino Acid Composition and Intrinsic Protein Disorder. Biochemistry 48, 164-172. doi:10.1021/bi801636y

Lundberg, I. E., Miller, F. W., Tjarnlund, A., and Bottai, M. (2016). Diagnosis and Classification of Idiopathic Inflammatory Myopathies. J. Intern. Med. 280, 39-51. doi:10.1111/joim.12524

Lyu, P., Zhang, S. D., Yuen, H. F., Mccrudden, C. M., Wen, Q., Chan, K. W., et al. (2017). Identification of TWIST-Interacting Genes in Prostate Cancer. Sci. China Life Sci. 60, 386-396. doi:10.1007/s11427-016-0262-6

Mabin, J. W., Woodward, L. A., Patton, R. D., Yi, Z., Jia, M., Wysocki, V. H., et al. (2018). The Exon Junction Complex Undergoes a Compositional Switch that Alters mRNP Structure and Nonsense-Mediated mRNA Decay Activity. Cell Rep 25, 2431-2446. doi:10.1016/j.celrep.2018.11.046

Milev, M. P., Ravichandran, M., Khan, M. F., Schriemer, D. C., and Mouland, A. J. (2012). Characterization of Staufen1 Ribonucleoproteins by Mass Spectrometry and Biochemical Analyses Reveal the Presence of Diverse Host Proteins Associated with Human Immunodeficiency Virus Type 1. Front. Microbiol. 3, 367. doi:10.3389/fmicb. 2012.00367

Miller, J. D., Bernstein, H. D., and Walter, P. (1994). Interaction of E. coli Ffh/4.5S Ribonucleoprotein and FtsY Mimics that of Mammalian Signal Recognition Particle and its Receptor. Nature 367, 657-659. doi:10.1038/367657a0

Miller, T., Al-Lozi, M. T., Lopate, G., and Pestronk, A. (2002). Myopathy with Antibodies to the Signal Recognition Particle: Clinical and Pathological Features. J. Neurol. Neurosurg. Psychiatry 73, 420-428. doi:10.1136/jnnp.73. 4.420

Mohr, T., Haudek-Prinz, V., Slany, A., Grillari, J., Micksche, M., and Gerner, C. (2017). Proteome Profiling in IL-1beta and VEGF-Activated Human Umbilical Vein Endothelial Cells Delineates the Interlink between Inflammation and Angiogenesis. PLoS One 12, e0179065. doi:10.1371/ journal.pone.0179065

Nabet, B. Y., Qiu, Y., Shabason, J. E., Wu, T. J., Yoon, T., Kim, B. C., et al. (2017), Exosome RNA Unshielding Couples Stromal Activation to Pattern Recognition Receptor Signaling in Cancer. Cell 170, 352-366. doi:10.1016/ j.cell.2017.06.031

Naji, S., Ambrus, G., Cimermancic, P., Reyes, J. R., Johnson, J. R., Filbrandt, R., et al. (2012). Host Cell Interactome of HIV-1 Rev Includes RNA Helicases Involved in Multiple Facets of Virus Production. Mol. Cel Proteomics 11. doi:10.1074/ mcp.m111.015313

Ohi, K., Shimada, T., Yasuyama, T., Kimura, K., Uehara, T., and Kawasaki, Y. (2017). Spatial and Temporal Expression Patterns of Genes Around Nine Neuroticism-Associated Loci. Prog. Neuropsychopharmacol. Biol. Psychiatry 77, 164-171. doi:10.1016/j.pnpbp.2017.04.019

Ohyama, T., Li, Y., Utsugi, T., Irie, S., Yamada, Y., and Sato, T. (1999). A Dual Topoisomerase Inhibitor, TAS-103, Induces Apoptosis in Human Cancer Cells. Jpn. J. Cancer Res. 90, 691-698. doi:10.1111/j.1349-7006.1999.tb00802.x

Onafuwa-Nuga, A. A., King, S. R., and Telesnitsky, A. (2005). Nonrandom Packaging of Host RNAs in Moloney Murine Leukemia Virus. J. Virol. 79, 13528-13537. doi:10.1128/jvi.79.21.13528-13537.2005

Onafuwa-Nuga, A. A., Telesnitsky, A., and King, S. R. (2006). 7SL RNA, but Not the 54-kd Signal Recognition Particle Protein, Is an Abundant Component of Both Infectious HIV-1 and Minimal Virus-like Particles. RNA 12, 542-546. doi:10.1261/rna.2306306

Oubridge, C., Kuglstatter, A., Jovine, L., and Nagai, K. (2002). Crystal Structure of SRP19 in Complex with the S Domain of SRP RNA and its Implication for the Assembly of the Signal Recognition Particle. Mol. Cel 9, 1251-1261. doi:10. 1016/s1097-2765(02)00530-0

Oyarbide, U., and Corey, S. J. (2018). SRP54 and a Need for a New Neutropenia Nosology. Blood 132, 1220-1222. doi:10.1182/blood-2018-07-859959

Park, S. S., Stankiewicz, P., Bi, W., Shaw, C., Lehoczky, J., Dewar, K., et al. (2002). Structure and Evolution of the Smith-Magenis Syndrome Repeat Gene Clusters, SMS-REPs. Genome Res. 12, 729-738. doi:10.1101/gr.82802

Peter Walter, G. B. (1983). Disassembly and Reconstitution of Signal Recognition Particle. Cell 34, 525-533. doi:10.1016/0092-8674(83)90385-9

Pool, M. R. (2005). Signal Recognition Particles in Chloroplasts, Bacteria, Yeast and Mammals (Review). Mol. Membr. Biol. 22, 3-15. doi:10.1080/ 09687860400026348

Pool, M. R., Stumm, J., Fulga, T. A., Sinning, I., and Dobberstein, B. (2002). Distinct Modes of Signal Recognition Particle Interaction with the Ribosome. Science 297, 1345-1348. doi:10.1126/science.1072366 
Poole, A. R., Vicino, I., Adachi, H., Yu, Y. T., and Hebert, M. D. (2017). Regulatory RNPs: a Novel Class of Ribonucleoproteins that Potentially Contribute to Ribosome Heterogeneity. Biol. Open 6, 1342-1354. doi:10. 1242/bio.028092

Prevo, R., Tiwana, G. S., Maughan, T. S., Buffa, F. M., Mckenna, W. G., and Higgins, G. S. (2017). Depletion of Signal Recognition Particle 72kDa Increases Radiosensitivity. Cancer Biol. Ther. 18, 425-432. doi:10.1080/15384047.2017. 1323587

Rapoport, T. A. (2007). Protein Translocation across the Eukaryotic Endoplasmic Reticulum and Bacterial Plasma Membranes. Nature 450, 663-669. doi:10. 1038/nature06384

Reeves, W. H., Nigam, S. K., and Blobel, G. (1986). Human Autoantibodies Reactive with the Signal-Recognition Particle. Proc. Natl. Acad. Sci. U S A. 83, 9507-9511. doi:10.1073/pnas.83.24.9507

Ren, Y. F., Li, G., Wu, J., Xue, Y. F., Song, Y. J., Lv, L., et al. (2012). Dicer-dependent Biogenesis of Small RNAs Derived from 7SL RNA. PLoS One 7, e40705. doi:10. 1371/journal.pone.0040705

Ren, Y. F., Li, G., Xue, Y. F., Zhang, X. J., Song, Y. J., Lv, L., et al. (2013). Decreased Dicer Expression Enhances SRP-Mediated Protein Targeting. PLoS One 8, e56950. doi:10.1371/journal.pone.0056950

Ren, Y. G., Wagner, K. W., Knee, D. A., Aza-Blanc, P., Nasoff, M., and Deveraux, Q. L. (2004). Differential Regulation of the TRAIL Death Receptors DR4 and DR5 by the Signal Recognition Particle. Mol. Biol. Cel 15, 5064-5074. doi:10.1091/ mbc.e04-03-0184

Rho, J. H., Qin, S., Wang, J. Y., and Roehrl, M. H. (2008). Proteomic Expression Analysis of Surgical Human Colorectal Cancer Tissues: Up-Regulation of PSB7, PRDX1, and SRP9 and Hypoxic Adaptation in Cancer. J. Proteome Res. 7, 2959-2972. doi:10.1021/pr8000892

Rider, L. G., Shah, M., Mamyrova, G., Huber, A. M., Rice, M. M., Targoff, I. N., et al. (2013). The Myositis Autoantibody Phenotypes of the Juvenile Idiopathic Inflammatory Myopathies. Medicine (Baltimore) 92, 223-243. doi:10.1097/ md.0b013e31829d08f9

Rivera, M., Ramos, Y., Rodriguez-Valentin, M., Lopez-Acevedo, S., Cubano, L. A., Zou, J., et al. (2017). Targeting Multiple Pro-apoptotic Signaling Pathways with Curcumin in Prostate Cancer Cells. PLoS One 12, e0179587. doi:10.1371/ journal.pone.0179587

Rojana-Udomsart, A., Mitrpant, C., Bundell, C., Price, L., Luo, Y. B., Fabian, V., et al. (2013). Complement-mediated Muscle Cell Lysis: a Possible Mechanism of Myonecrosis in Anti-SRP Associated Necrotizing Myopathy (ASANM). J. Neuroimmunol 264, 65-70. doi:10.1016/j.jneuroim.2013.08.008

Rolland, D., Bouamrani, A., Houlgatte, R., Barbarat, A., Ramus, C., Arlotto, M., et al. (2011). Identification of Proteomic Signatures of Mantle Cell Lymphoma, Small Lymphocytic Lymphoma, and Marginal Zone Lymphoma Biopsies by Surface Enhanced Laser Desorption/ionization-Time of Flight Mass Spectrometry. Leuk. Lymphoma 52, 648-658. doi:10.3109/10428194.2010. 549256

Romisch, K., Miller, F. W., Dobberstein, B., and High, S. (2006). Human Autoantibodies against the $54 \mathrm{kDa}$ Protein of the Signal Recognition Particle Block Function at Multiple Stages. Arthritis Res. Ther. 8, R39. doi:10.1186/ar1895

Rosenbluh, J., Mercer, J., Shrestha, Y., Oliver, R., Tamayo, P., Doench, J. G., et al. (2016). Genetic and Proteomic Interrogation of Lower Confidence Candidate Genes Reveals Signaling Networks in Beta-Catenin-Active Cancers. Cell Syst 3, 302-316. doi:10.1016/j.cels.2016.09.001

Rudel, T., and Bokoch, G. M. (1997). Membrane and Morphological Changes in Apoptotic Cells Regulated by Caspase-Mediated Activation of PAK2. Science 276, 1571-1574. doi:10.1126/science.276.5318.1571

Saraogi, I., and Shan, S. O. (2011). Molecular Mechanism of Co-translational Protein Targeting by the Signal Recognition Particle. Traffic 12, 535-542. doi:10.1111/j.1600-0854.2011.01171.x

Schmaltz-Panneau, B., Pagnier, A., Clauin, S., Buratti, J., Marty, C., Fenneteau, O., et al. (2021). Identification of Biallelic Germline Variants of SRP68 in a Sporadic Case with Severe Congenital Neutropenia. Haematologica 106, 1216-1219. doi:10.3324/haematol.2020.247825

Schürch, C., Schaefer, T., Müller, J. S., Hanns, P., Arnone, M., Dumlin, A., et al. (2021). SRP54 Mutations Induce Congenital Neutropenia via DominantNegative Effects on XBP1 Splicing. Blood 137, 1340-1352. doi:10.1182/ blood.2020008115
Shah, S. P., Morin, R. D., Khattra, J., Prentice, L., Pugh, T., Burleigh, A., et al. (2009). Mutational Evolution in a Lobular Breast Tumour Profiled at Single Nucleotide Resolution. Nature 461, 809-813. doi:10.1038/nature08489

Siegel, V., and Walter, P. (1988). Functional Dissection of the Signal Recognition Particle. Trends Biochem. Sci. 13, 314-316. doi:10.1016/0968-0004(88)90127-2

Singh, J., Dani, H. M., Sharma, R., and Steinberg, P. (2006). Inhibition of the Biosynthesis of SRP Polypeptides and Secretory Proteins by Aflatoxin B1 Can Disrupt Protein Targeting. Cell Biochem Funct 24, 507-510. doi:10.1002/cbf. 1285

Singh, J., Singh, S., Dani, H. M., Sharma, R., and Steinberg, P. (2005). Interactions of Aflatoxin B1 with SRP Components Can Disrupt Protein Targeting. Cel Biochem Funct 23, 9-13. doi:10.1002/cbf.1120

Srivastava, M., and Pollard, H. B. (1999). Molecular Dissection of Nucleolin's Role in Growth and Cell Proliferation: New Insights. FASEB J 13, 1911-1922. doi:10. 1096/fasebj.13.14.1911

Srivastava, M., Torosyan, Y., Eidelman, O., Jozwik, C., Pollard, H. B., and Mannon, R. (2015). Reduced PARP1 as a Serum Biomarker for Graft Rejection in Kidney Transplantation. J. Proteomics Bioinform 8, 031-038. doi:10.4172/jpb.1000350

Strub, K., and Walter, P. (1990). Assembly of the Alu Domain of the Signal Recognition Particle (SRP): Dimerization of the Two Protein Components Is Required for Efficient Binding to SRP RNA. Mol. Cel Biol 10, 777-784. doi:10. $1128 / \mathrm{mcb} \cdot 10.2 .777$

Su, Z. Z., Kang, D. C., Chen, Y., Pekarskaya, O., Chao, W., Volsky, D. J., et al. (2003). Identification of Gene Products Suppressed by Human Immunodeficiency Virus Type 1 Infection or Gp120 Exposure of Primary Human Astrocytes by Rapid Subtraction Hybridization. J. Neurovirol. 9, 372-389. doi:10.1080/13550280390201263

Suzuki, S., Nishikawa, A., Kuwana, M., Nishimura, H., Watanabe, Y., Nakahara, J., et al. (2015). Inflammatory Myopathy with Anti-signal Recognition Particle Antibodies: Case Series of 100 Patients. Orphanet J. Rare Dis. 10, 61. doi:10. 1186/s13023-015-0277-y

Tajima, S., Lauffer, L., Rath, V. L., and Walter, P. (1986). The Signal Recognition Particle Receptor Is a Complex that Contains Two Distinct Polypeptide Chains. J. Cel Biol 103, 1167-1178. doi:10.1083/jcb.103.4.1167

Talhouarne, G. J. S., and Gall, J. G. (2018). 7SL RNA in Vertebrate Red Blood Cells. RNA 24, 908-914. doi:10.1261/rna.065474.117

Targoff, I. N., Johnson, A. E., and Miller, F. W. (1990). Antibody to Signal Recognition Particle in Polymyositis. Arthritis Rheum. 33, 1361-1370. doi:10.1002/art.1780330908

Targoff, I. N. (2000). Update on Myositis-specific and Myositis-Associated Autoantibodies. Curr. Opin. Rheumatol. 12, 475-481. doi:10.1097/00002281200011000-00001

Tian, C., Wang, T., Zhang, W., and Yu, X. F. (2007). Virion Packaging Determinants and Reverse Transcription of SRP RNA in HIV-1 Particles. Nucleic Acids Res. 35, 7288-7302. doi:10.1093/nar/gkm816

Tiwana, G. S., Prevo, R., Buffa, F. M., Yu, S., Ebner, D. V., Howarth, A., et al. (2015). Identification of Vitamin B1 Metabolism as a Tumor-specific Radiosensitizing Pathway Using a High-Throughput Colony Formation Screen. Oncotarget 6, 5978-5989. doi:10.18632/oncotarget.3468

Tsai, P. C., Huang, S. W., Tsai, H. L., Ma, C. J., Hou, M. F., Yang, I. P., et al. (2014). The Association between DNA Copy Number Aberrations at Chromosome 5q22 and Gastric Cancer. PLoS One 9, e106624. doi:10.1371/journal.pone. 0106624

Turpaev, K., Glatigny, A., Bignon, J., Delacroix, H., and Drapier, J. C. (2010). Variation in Gene Expression Profiles of Human Monocytic U937 Cells Exposed to Various Fluxes of Nitric Oxide. Free Radic. Biol. Med. 48, 298-305. doi:10.1016/j.freeradbiomed.2009.10.054

Ulrich-Merzenich, G., Kelber, O., Koptina, A., Freischmidt, A., Heilmann, J., Muller, J., et al. (2012). Novel Neurological and Immunological Targets for Salicylate-Based Phytopharmaceuticals and for the Anti-depressant Imipramine. Phytomedicine 19, 930-939. doi:10.1016/j.phymed.2012.05.004

Utsugi, T., Aoyagi, K., Asao, T., Okazaki, S., Aoyagi, Y., Sano, M., et al. (1997). Antitumor Activity of a Novel Quinoline Derivative, TAS-103, with Inhibitory Effects on Topoisomerases I and II. Jpn. J. Cancer Res. 88, 992-1002. doi:10. 1111/j.1349-7006.1997.tb00320.x

Utz, P. J., and Anderson, P. (1998). Posttranslational Protein Modifications, Apoptosis, and the Bypass of Tolerance to Autoantigens. Arthritis Rheum. 41, 1152-1160. doi:10.1002/1529-0131(199807)41:7<1152::aid-art3>3.0.co;2-1 
Utz, P. J., Hottelet, M., Le, T. M., Kim, S. J., Geiger, M. E., Van Venrooij, W. J., et al. (1998). The 72-kDa Component of Signal Recognition Particle Is Cleaved during Apoptosis. J. Biol. Chem. 273, 35362-35370. doi:10.1074/jbc.273.52. 35362

Vatakuti, S., Pennings, J. L., Gore, E., Olinga, P., and Groothuis, G. M. (2016). Classification of Cholestatic and Necrotic Hepatotoxicants Using Transcriptomics on Human Precision-Cut Liver Slices. Chem. Res. Toxicol. 29, 342-351. doi:10.1021/acs.chemrestox.5b00491

Wagstaff, K. M., Sivakumaran, H., Heaton, S. M., Harrich, D., and Jans, D. A. (2012). Ivermectin Is a Specific Inhibitor of Importin Alpha/beta-Mediated Nuclear Import Able to Inhibit Replication of HIV-1 and Dengue Virus. Biochem. J. 443, 851-856. doi:10.1042/bj20120150

Walter, P., and Blobel, G. (1983). Disassembly and Reconstitution of Signal Recognition Particle. Cell 34, 525-533. doi:10.1016/0092-8674(83)90385-9

Walter, P., and Blobel, G. (1981). Translocation of Proteins across the Endoplasmic Reticulum III. Signal Recognition Protein (SRP) Causes Signal Sequencedependent and Site-specific Arrest of Chain Elongation that Is Released by Microsomal Membranes. J. Cel Biol 91, 557-561. doi:10.1083/jcb.91.2.557

Wang, F., Li, J., Fan, S., Jin, Z., and Huang, C. (2020). Targeting Stress Granules: A Novel Therapeutic Strategy for Human Diseases. Pharmacol. Res. 161, 105143. doi:10.1016/j.phrs.2020.105143

Wang, N., Lin, K. K., Lu, Z., Lam, K. S., Newton, R., Xu, X., et al. (2007). The LIMOnly Factor LMO4 Regulates Expression of the BMP7 Gene through an HDAC2-dependent Mechanism, and Controls Cell Proliferation and Apoptosis of Mammary Epithelial Cells. Oncogene 26, 6431-6441. doi:10. 1038/sj.onc.1210465

Wang, Q., Duan, F., Liu, P., Wang, P. F., and Wang, M. X. (2016). Expression of Anti-SRP19 Antibody in Muscle Tissues from Patients with Autoimmune Necrotizing Myopathy. Genet. Mol. Res. 15. doi:10.4238/gmr.15038307

Wang, T., Tian, C., Zhang, W., Luo, K., Sarkis, P. T., Yu, L., et al. (2007). 7SL RNA Mediates Virion Packaging of the Antiviral Cytidine Deaminase APOBEC3G. J. Virol. 81, 13112-13124. doi:10.1128/jvi.00892-07

Wang, T., Tian, C., Zhang, W., Sarkis, P. T., and Yu, X. F. (2008a). Interaction with 7SL RNA but Not with HIV-1 Genomic RNA or P Bodies Is Required for APOBEC3F Virion Packaging. J. Mol. Biol. 375, 1098-1112. doi:10.1016/j.jmb. 2007.11.017

Wang, T., Zhang, W., Tian, C., Liu, B., Yu, Y., Ding, L., et al. (2008b). Distinct Viral Determinants for the Packaging of Human Cytidine Deaminases APOBEC3G and APOBEC3C. Virology 377, 71-79. doi:10.1016/j.virol.2008.04.012

Wang, Y. Q., Ren, Y. F., Song, Y. J., Xue, Y. F., Zhang, X. J., Cao, S. T., et al. (2014). MicroRNA-581 Promotes Hepatitis B Virus Surface Antigen Expression by Targeting Dicer and EDEM1. Carcinogenesis 35, 2127-2133. doi:10.1093/ carcin/bgu128

Weichenrieder, O., Wild, K., Strub, K., and Cusack, S. (2000). Structure and Assembly of the Alu Domain of the Mammalian Signal Recognition Particle. Nature 408, 167-173. doi:10.1038/35041507

White, R. J. (2004). RNA Polymerase III Transcription and Cancer. Oncogene 23, 3208-3216. doi:10.1038/sj.onc.1207547

Wild, K., Sinning, I., and Cusack, S. (2001). Crystal Structure of an Early ProteinRNA Assembly Complex of the Signal Recognition Particle. Science 294, 598-601. doi:10.1126/science.1063839

Woodcock, C. L., Skoultchi, A. I., and Fan, Y. (2006). Role of Linker Histone in Chromatin Structure and Function: H1 Stoichiometry and Nucleosome Repeat Length. Chromosome Res. 14, 17-25. doi:10.1007/s10577-005-1024-3

Yang, Y., Cheng, J., Ren, H., Zhao, H., Gong, W., and Shan, C. (2016). Tumor FOXP3 Represses the Expression of Long Noncoding RNA 7SL. Biochem. Biophys. Res. Commun. 472, 432-436. doi:10.1016/j.bbrc.2015.12.082

Ye, F., Liang, J., Li, J., Li, H., and Sheng, W. (2020). Development and Validation of a Five-Gene Signature to Predict Relapse-free Survival in Multiple Sclerosis. Front. Neurol. 11, 579683. doi:10.3389/fneur.2020.579683

Yin, J., Iakhiaeva, E., Menichelli, E., and Zwieb, C. (2007). Identification of the RNA Binding Regions of SRP68/72 and SRP72 by Systematic Mutagenesis of Human SRP RNA. RNA Biol. 4, 154-159. doi:10.4161/rna.4.3.5428
Yoshida, M., Kabe, Y., Wada, T., Asai, A., and Handa, H. (2008). A New Mechanism of 6-((2-(dimethylamino)ethyl)amino)-3-Hydroxy-7hIndeno(2,1-C)quinolin-7-One Dihydrochloride (TAS-103) Action Discovered by Target Screening with Drug-Immobilized Affinity Beads. Mol. Pharmacol. 73, 987-994. doi:10.1124/mol.107.043307

Zahr, Z. A., and Baer, A. N. (2011). Malignancy in Myositis. Curr. Rheumatol. Rep. 13, 208-215. doi:10.1007/s11926-011-0169-7

Zalfa, F., Adinolfi, S., Napoli, I., Kuhn-Holsken, E., Urlaub, H., Achsel, T., et al. (2005). Fragile X Mental Retardation Protein (FMRP) Binds Specifically to the Brain Cytoplasmic RNAs BC1/BC200 via a Novel RNA-Binding Motif. J. Biol. Chem. 280, 33403-33410. doi:10.1074/jbc. m504286200

Zappa, F., Wilson, C., Di Tullio, G., Santoro, M., Pucci, P., Monti, M., et al. (2019). The TRAPP Complex Mediates Secretion Arrest Induced by Stress Granule Assembly.EMBO J. 38, e101704. doi:10.15252/embj.2019101704

Zekri, A. R., Hassan, Z. K., Bahnassy, A. A., Khaled, H. M., El-Rouby, M. N., Haggag, R. M., et al. (2015). Differentially Expressed Genes in Metastatic Advanced Egyptian Bladder Cancer. Asian Pac. J. Cancer Prev. 16, 3543-3549. doi:10.7314/apjcp.2015.16.8.3543

Zhang, P., Branson, O. E., Freitas, M. A., and Parthun, M. R. (2016). Identification of Replication-dependent and Replication-independent Linker Histone Complexes: Tpr Specifically Promotes Replication-dependent Linker Histone Stability. BMC Biochem. 17, 18. doi:10.1186/s12858-016-0074-9

Zhang, Q., Ma, J., Liu, H., He, D., Chen, L., Wu, H., et al. (2018). Comparative Analysis of Gene Expression Profiles of Human Dental Fluorosis and KashinBeck Disease. Sci. Rep. 8, 170. doi:10.1038/s41598-017-18519-z

Zhang, X. D., Franco, A., Myers, K., Gray, C., Nguyen, T., and Hersey, P. (1999). Relation of TNF-Related Apoptosis-Inducing Ligand (TRAIL) Receptor and FLICE-Inhibitory Protein Expression to TRAIL-Induced Apoptosis of Melanoma. Cancer Res. 59, 2747-2753.

Zhang, Y., Yao, K., Yu, Y., Ni, S., Zhang, L., Wang, W., et al. (2013). Effects of 1.8 $\mathrm{GHz}$ Radiofrequency Radiation on Protein Expression in Human Lens Epithelial Cells. Hum. Exp. Toxicol. 32, 797-806. doi:10.1177/ 0960327112472353

Zhao, G., Hou, J., Xu, G., Xiang, A., Kang, Y., Yan, Y., et al. (2017). Cellular microRNA miR-10a-5p Inhibits Replication of Porcine Reproductive and Respiratory Syndrome Virus by Targeting the Host Factor Signal Recognition Particle 14. J. Gen. Virol. 98, 624-632. doi:10.1099/jgv.0. 000708

Zhao, P., Yin, H., Tao, C., Chen, P., Song, Y., Yang, W., et al. (2015). Latent Pathways Identification by Microarray Expression Profiles in ThyroidAssociated Ophthalmopathy Patients. Endocr. Pathol. 26, 200-210. doi:10. 1007/s12022-015-9373-8

Zhao, Y., Yu, J., Zhao, J., Chen, X., Xiong, N., Wang, T., et al. (2018). Intragenic Transcriptional Cis-Antagonism across SLC6A3. Mol. Neurobiol. 56, 4051-4060. doi:10.1007/s12035-018-1357-5

Zwieb, C. (1985). The Secondary Structure of the 7SL RNA in the Signal Recognition Particle: Functional Implications. Nucleic Acids Res. 13, 6105-6124. doi:10.1093/nar/13.17.6105

Zwieb, C., Van Nues, R. W., Rosenblad, M. A., Brown, J. D., and Samuelsson, T. (2005). A Nomenclature for All Signal Recognition Particle RNAs. RNA 11, 7-13. doi:10.1261/rna.7203605

Conflict of Interest: The authors declare that the research was conducted in the absence of any commercial or financial relationships that could be construed as a potential conflict of interest.

Copyright (c) 2021 Faoro and Ataide. This is an open-access article distributed under the terms of the Creative Commons Attribution License (CC BY). The use, distribution or reproduction in other forums is permitted, provided the original author(s) and the copyright owner(s) are credited and that the original publication in this journal is cited, in accordance with accepted academic practice. No use, distribution or reproduction is permitted which does not comply with these terms. 